\title{
Hypersonic Laminar Boundary Layer Velocimetry with Discrete Roughness on a Flat Plate
}

\author{
Brett F. Bathel ${ }^{1}$ \\ University of Virginia, Hampton, Virginia, 23681-21991 \\ Paul M. Danehy ${ }^{2}$, Jennifer A. Inman ${ }^{3}$, A. Neal Watkins ${ }^{4}$, Stephen B. Jones ${ }^{5}$, William E. Lipford ${ }^{6}$ \\ NASA Langley Research Center, Hampton, Virginia, 23681-21991 \\ Kyle Z. Goodman ${ }^{7}$ \\ ATK, Hampton, VA, 23681-21991 \\ Christopher B. Ivey ${ }^{8}$ \\ Johns Hopkins University, Baltimore, MD, 21218 \\ and \\ Christopher P. Goyne ${ }^{9}$ \\ University of Virginia, Charlottesville, Virginia, 22904
}

\begin{abstract}
Laminar boundary layer velocity measurements are made on a 10-degree half-angle wedge in a Mach 10 flow. Two types of discrete boundary layer trips were used to perturb the boundary layer gas. The first was a $2-\mathrm{mm}$ tall, 4-mm diameter cylindrical trip. The second was a scaled version of the Orbiter Boundary Layer Transition (BLT) Detailed Test Objective (DTO) trip. Both 1-mm and 2.5-mm tall BLT DTO trips were tested. Additionally, side-view and plan-view axial boundary layer velocity measurements were made in the absence of these tripping devices. The free-stream unit Reynolds numbers tested for the cylindrical trips were $1.7 \times 10^{6} \mathrm{~m}^{-1}$ and $3.3 \times 10^{6} \mathrm{~m}^{-1}$. The free-stream unit Reynolds number tested for the BLT DTO trips was $1.7 \times 10^{6} \mathrm{~m}^{-1}$. The angle of attack was kept at approximately 5-degrees for most of the tests resulting in a Mach number of approximately 8.3. These combinations of unit Reynolds numbers and angle of attack resulted in laminar flowfields. To study the precision of the measurement technique, the angle of attack was varied during one run. Nitric-oxide (NO) molecular tagging velocimetry (MTV) was used to obtain averaged axial velocity values and associated uncertainties. These uncertainties are as low as $20 \mathrm{~m} / \mathrm{s}$. An interline, progressive scan CCD camera was used to obtain separate images of the initial reference and shifted NO molecules that had been tagged by the laser. The CCD configuration allowed for sub-microsecond sequential acquisition of both images. The maximum planar spatial resolution achieved for the side-view velocity measurements was $0.07-\mathrm{mm}$ in the wall-normal direction by $1.45-\mathrm{mm}$ in the streamwise direction with a spatial depth of $0.5-\mathrm{mm}$. For the plan-view measurements, the maximum planar spatial resolution in the spanwise and streamwise directions was $0.69-\mathrm{mm}$ by $1.28-\mathrm{mm}$, respectively, with a
\end{abstract}

${ }^{1}$ Graduate Student, National Institute of Aerospace/University of Virginia, MS 493, AIAA Student Member.

${ }^{2}$ Research Scientist, Advanced Sensing and Optical Measurement Branch, MS 493, AIAA Associate Fellow.

${ }^{3}$ Research Scientist, Advanced Sensing and Optical Measurement Branch, MS 493, AIAA Member.

${ }^{4}$ Research Scientist, Advanced Sensing and Optical Measurement Branch, MS 493, AIAA Member.

${ }^{5}$ Technician, Advanced Sensing and Optical Measurement Branch, MS 493.

${ }^{6}$ Technician, Advanced Sensing and Optical Measurement Branch, MS 493.

${ }^{7}$ Chemist, Advanced Sensing and Optical Measurement Branch, MS 493, AIAA Member.

${ }^{8}$ Undergraduate Student, Mechanical Engineering, 223 Latrobe Hall 3400 N. Charles St., AIAA Student Member.

${ }^{9}$ Research Assistant Professor, Mechanical and Aerospace Engineering, Aerospace Research Laboratory, PO Box 400248, AIAA Associate Fellow. 
spatial depth of $0.5-\mathrm{mm}$. Temperature sensitive paint (TSP) measurements are provided to compliment the velocity data and to provide further insight into the behavior of the boundary layers. The experiments were performed at the NASA Langley Research Center 31-Inch Mach 10 Air tunnel.

\section{Introduction}

$\mathrm{T}$ HE ability to predict laminar-to-turbulent boundary layer transition is of great importance to the design of aerospace vehicles capable of traveling at hypersonic velocities. Of primary concern is the increased heat transfer to the vehicle surface resulting from such a transition. However, understanding of the mechanisms responsible for the initiation of this transition process is limited. Currently, no general method exists which is capable of consistently computing even the most basic of transition parameters, the transition location, over a range of hypersonic flow conditions. While some success in developing combined empirical and analytical tools for predicting transition location has been achieved, these efforts are typically only for very specific geometries and flow conditions, such as with NASA's Orbiter Boundary Layer Transition Prediction Tool. ${ }^{1}$ The difficulty in creating an all-encompassing empirically-based, theoretically-based, or combined prediction tool is compounded by the sheer number of flow variables that influence such a computation. The ultimate goal of transition research is to determine how each variable contributes and interacts to promote the growth of instabilities in the boundary layer, eventually leading to breakdown of the laminar nature of the viscous region and the onset of transition.

Computational fluid dynamic (CFD) tools are being designed to capture flow physics, to characterize the nature of laminar boundary layer instabilities, and to predict transition-to-turbulence. Such tools are first typically computed for simple geometries that can be compared and validated against experimental datasets. There is a need for high-quality data sets for such comparisons. A recent example of a hypersonic boundary layer CFD solution was a simulation performed on a flat plate with a cylindrical protuberance. ${ }^{2}$ This work has been compared qualitatively with nitric oxide planar laser-induced fluorescence (NO PLIF) flow visualization ${ }^{3}$ at a specific off-body location. However, the ability to perform off-body quantitative measurements in hypersonic flows can be complicated by the extreme dynamic and thermodynamic conditions present in hypersonic test facilities and the limited optical access to the test section. Therefore, measurement techniques that can overcome the challenges presented by these environments must be developed and applied to provide the hypersonic flow datasets necessary for computational validation.

NASA's interest in transitional flows is evidenced by the recent Space Shuttle Orbiter (STS-119 and STS-128) flight experiments ${ }^{4,5}$ involving a boundary layer tripping device which was placed on the windward side of the starboard wing. This trip ensured transition of the boundary layer across a region of the Orbiter with resulting in increased heating patterns. During re-entry, HYTHIRM ${ }^{6,7}$ (Hypersonic Thermodynamic Infrared Measurement) provided global heating maps of the underside of the Orbiter to aid in determination of transition locations over a narrow range of re-entry Mach numbers. Initial computational efforts have sought to describe the off-body flow conditions encountered with a scaled, 1-mm tall Orbiter Boundary Layer Transition Detailed Test Objective (BLT DTO) geometry. ${ }^{2,8,9}$ These solutions have also been compared with NO PLIF flow visualizations. ${ }^{10,11}$ Yet quantitative data is still needed to further validate computational predictions.

The purpose of this paper is to provide quantitative velocity data for validation and improvement of existing computational codes. Specifically, this paper provides averaged and instantaneous planar, axial velocities and uncertainties of both unperturbed and perturbed hypersonic, flat-plate laminar boundary layers. This paper represents the first application of the NO MTV technique to NASA Langley's 31-Inch Mach 10 Air Tunnel with the objective of obtaining multiple velocity datasets. The perturbed boundary-layer velocity measurements, for both a cylindrical trip and two Orbiter BLT DTO trips, will serve as a database for computational studies of these discrete roughness geometries in hypersonic boundary layers. In addition to velocity measurements, heat transfer data obtained from temperature sensitive paint (TSP) measurements are provided. These measurements correspond to all of the 2-mm tall, 4-mm diameter cylindrical trip experiments and at two unit Reynolds number conditions in unperturbed flows. This data is meant to complement the velocity data and will provide a better understanding of the flowfield in the immediate vicinity of the trips.

A 1-dimensional cross-correlation method, similar to that discussed in Ref. 12, was used to calculate both averaged and instantaneous velocity values. The full velocity and uncertainty calculations, corresponding to the averaged and instantaneous velocity profiles, have been presented in detail in Ref. 13. The experimental data presented in this paper were obtained using a 10-degree half-angle wedge model oriented such that the plate angle, (angle of the model surface, over which the measurements were made, with respect to the free stream), was +5 degrees. The selection of this plate angle was due to the technique being pressure limited, as described in Ref. 13. 


\section{Experimental Setup}

\section{A. Wind Tunnel Facility}

The 31-Inch Mach 10 Air Tunnel is an electrically-heated blowdown facility located at NASA Langley Research Center in Hampton, Virginia, USA. The full details of this facility can be found in the paper by Micol, ${ }^{14}$ a brief summary of which is provided here. The facility has a nominal Mach number of 10 and a 31-inch square test section and operates on electrically heated, compressed air. Large windows, transparent in the ultraviolet, form three walls (including top, side and bottom) of the test section with the fourth wall formed by the model injection system. The top window allows for the laser sheet to pass through the tunnel section, while the side window allows for imaging of the flow region of interest. The model is side-mounted to the fourth wall. Run durations for the current tests were about one minute. Two facility stagnation pressures, $\mathrm{P}_{0}$, of $2.41 \mathrm{MPa}(350 \mathrm{psia})$ and $4.96 \mathrm{MPa}$ (720 psia) were used in this investigation. The nominal stagnation temperature, $\mathrm{T}_{0}$, was $1,000 \mathrm{~K}(1,800$ Rankine) for the experiments described herein. Based upon the stagnation pressure conditions of $2.41 \mathrm{MPa}$ and $4.96 \mathrm{MPa}$, the freestream Mach number were 9.68 and 9.81 , respectively. The freestream pressures for the two stagnation pressure conditions were $68.3 \pm 0.3 \mathrm{~Pa}\left(9.90 \times 10^{-3} \mathrm{psi}\right)$ and $130.1 \pm 0.3 \mathrm{~Pa}\left(18.87 \times 10^{-3} \mathrm{psi}\right)$, respectively. The freestream temperature was $52.0 \pm 1.5 \mathrm{~K}$ (93.6 Rankine). The freestream velocity was $1404.5 \pm 12.0 \mathrm{~m} / \mathrm{s}$.

Based upon the freestream conditions, inviscid oblique shock relations indicate an edge Mach number of 8.1. Using the same relations, the edge velocities were estimated to be $1389 \mathrm{~m} / \mathrm{s}$.

\section{B. Wind Tunnel Model and Trip Configurations}

The first portion of the experiment was conducted using a 10-degree half-angle wedge model with a sharp leading edge, similar to that described in Ref. 3. The upper surface of the wedge model, over which the NO PLIF measurements were made, was essentially a flat plate that was $127.0 \mathrm{~mm}(5 \mathrm{in}$.) wide and $162.5 \mathrm{~mm}$ (6.4 in.) long with a +5 -degree plate angle for all runs. For the tripped experiments, a $\mathrm{k}=2$-mm tall, 4-mm wide cylindrical boundary layer trip was positioned along the centerline, with the center of the trip located 75.4-mm downstream of the leading edge. Pure nitric oxide $(100 \% \mathrm{NO})$ was seeded into the laminar boundary layer from an 11-mm-long, $0.81-\mathrm{mm}$-wide slot centered on the axis of symmetry and located 29.4-mm downstream of the leading edge. The flowrates supplied through this slot (listed in Table 1) were designed to minimally perturb the boundary layer flow, based upon surface heat transfer measurements performed by Berry et al. ${ }^{15}$ using a similar gas supply configuration. Analysis of these heat transfer measurement results and the boundary layer perturbation associated with the present wedge model are discussed by Danehy et al., ${ }^{16}$ which also provides measurements of boundary layer thickness, $\delta$, and hence $\mathrm{k} / \delta$ values provided in Table 1 .

The second portion of the experiment again used the same 10-degree half-angle wedge model, but with a $1.00 \pm 0.02 \mathrm{~mm}(0.039 \mathrm{in}$.) tall and a $2.5 \pm 0.02 \mathrm{~mm}(0.098 \mathrm{in}$.) tall BLT DTO trip. The windward edge of each trip was located $74.8 \mathrm{~mm}$ downstream of the leading edge of the model. The outermost width of the 1-mm trip was $11.3 \pm 0.1 \mathrm{~mm}(0.45 \mathrm{in}$.) while the full-width at half maximum was $10.4 \pm 0.1 \mathrm{~mm}(0.408 \mathrm{in}$.). For the 2.5 -mm trip, the outermost width was $28.3 \pm 0.1 \mathrm{~mm}$ (1.11 in.) with a full-width at half maximum of $26.0 \pm 0.1 \mathrm{~mm}$ (1.02 in.). Each trip was aligned at a 45-degree angle with respect to the long axis. These trips were manufactured using a stereo lithography apparatus (SLA) at the Fabrication Shop at NASA Langley Research Center. The SLA material was a high-temperature nanocomposite material (NanoForm ${ }^{\mathrm{TM}} 15120$ from DSM Somos).

Table 1. Test parameters.

\begin{tabular}{cccccccc}
\hline \hline Test - Run & Trip & $\mathrm{k}$ & $\mathrm{k} / \delta$ & $\mathrm{M}_{\mathrm{e}}$ & $\mathrm{Re}_{\mathrm{x}}$ & Flow Rate (Composition) & Test Type \\
\hline $462-15$ & - & - & - & 8.1 & $1.7 \times 10^{6} \mathrm{~m}^{-1}$ & 350 SCCM $(100 \%$ NO) & NO PLIF \\
$462-17$ & - & - & - & 8.1 & $3.3 \times 10^{6} \mathrm{~m}^{-1}$ & 300 SCCM $(100 \%$ NO) & NO PLIF \\
$462-18$ & Cylinder & $2-\mathrm{mm}$ & 0.64 & 8.1 & $1.7 \times 10^{6} \mathrm{~m}^{-1}$ & 150 SCCM $(100 \%$ NO) & NO PLIF \\
$462-27$ & - & - & - & 8.1 & $1.7 \times 10^{6} \mathrm{~m}^{-1}$ & 150 SCCM $(100 \%$ NO) & NO PLIF \\
$462-25$ & Cylinder & $2-\mathrm{mm}$ & 0.64 & 8.1 & $1.7 \times 10^{6} \mathrm{~m}^{-1}$ & 150 SCCM $(100 \%$ NO) & NO PLIF \\
$462-26$ & Cylinder & $2-\mathrm{mm}$ & 0.89 & 8.1 & $3.3 \times 10^{6} \mathrm{~m}^{-1}$ & 150 SCCM $(100 \%$ NO) & NO PLIF \\
$462-30$ & - & - & - & 8.1 & $1.7 \times 10^{6} \mathrm{~m}^{-1}$ & - & TSP \\
$462-29$ & Cylinder & $2-\mathrm{mm}$ & 0.64 & 8.1 & $1.7 \times 10^{6} \mathrm{~m}^{-1}$ & - & TSP \\
$462-31$ & Cylinder & $2-\mathrm{mm}$ & 0.89 & 8.1 & $3.3 \times 10^{6} \mathrm{~m}^{-1}$ & - & TSP \\
$462-33$ & Cylinder & $2-\mathrm{mm}$ & 0.89 & 8.1 & $3.3 \times 10^{6} \mathrm{~m}^{-1}$ & 300 SCCM $\left(100 \% \mathrm{~N}_{2}\right)$ & TSP \\
$467-3$ & BLT DTO & $1-\mathrm{mm}$ & 0.32 & 8.1 & $1.7 \times 10^{6} \mathrm{~m}^{-1}$ & 150 SCCM $(100 \%$ NO) & NO PLIF \\
$467-4$ & BLT DTO & $2.5-\mathrm{mm}$ & 0.80 & 8.1 & $1.7 \times 10^{6} \mathrm{~m}^{-1}$ & 150 SCCM $(100 \%$ NO) & NO PLIF \\
\hline \hline
\end{tabular}




\section{PLIF Imaging System}

The 532-nm output from a pulsed Spectra Physics Pro-230 Nd:YAG laser was used to pump a Sirah Cobra Stretch dye laser to achieve a $622-\mathrm{nm}$ output beam. This output was mixed with $355-\mathrm{nm}$ light from the Nd:YAG in a Sirah Frequency Conversion Unit to produce $\sim 5 \mathrm{~mJ}$ per pulse at approximately $226 \mathrm{~nm}$. This beam was directed to sheet-forming optics mounted above the tunnel test section. The duration of the pulse at this wavelength was approximately $9.5 \mathrm{~ns}$.

To form a laser sheet, the collimated $226 \mathrm{~nm}$ beam was passed through a 36-mm focal length cylindrical lens, which focused and then diverged the beam, expanding it in one direction while leaving it collimated in the other. A $1-\mathrm{m}$ focal length spherical lens then collimated the diverging axis of the beam and focused the other axis into a thin sheet approximately $75-\mathrm{mm}$ wide by $0.5-\mathrm{mm}$ thick. To tag multiple lines of NO in the test section for a velocimetry measurement, a 50-mm-long, LaserOptik GmbH diffusion welded lens array of 25, 1-m focal length cylindrical lenses focused the laser sheet into 25 lines. The lens array had an anti-reflection coating.

Two different laser orientation and camera views were used to obtain the MTV images. In both cases the camera was perpendicular to the laser sheet lines. The camera was first oriented such that axial velocity measurements were performed along a series of lines perpendicular to the plate and aligned with the centerline. This view is hereafter referred to as the side-view orientation. The second orientation was with the laser lines running parallel to the model surface in the spanwise direction, such that the axial velocity could be obtained. This view is hereafter referred to as the plan-view orientation. The lines formed in the cylindrical trip configuration for the side-view (Test 462, Runs 15, 17, and 18) and plan-view (Test 462, Runs 25, 26, and 27) camera orientations had widths of approximately $1.45 \pm 0.19 \mathrm{~mm}$ and $0.82 \pm 0.11 \mathrm{~mm}$ at FWHM, respectively. The approximate separation distance between each line in was $3.28 \pm 0.24 \mathrm{~mm}$ and $2.16 \pm 0.10 \mathrm{~mm}$, respectively. For the BLT DTO trip configuration (Test 467, Runs 3 and 4), the lines formed had FWHM widths of approximately $1.06 \pm 0.22 \mathrm{~mm}$ with a separation distance between each line of approximately $2.96 \pm 0.24 \mathrm{~mm}$.

To image the tagged lines in both tests, a Cooke DiCAM-PRO camera, utilizing an intensified 1280x1024 pixel array interline progressive scan CCD, was used. The camera was fitted with a $100-\mathrm{mm}$ focal length, F/2.0 B. Halle Nachfl. lens. Spatial resolutions achieved with this camera/lens combination varied from $15.7 \mathrm{pixels} / \mathrm{mm}$ (398.8 pixels/inch) to 17.5 pixels $/ \mathrm{mm}$ (444.5 pixels/inch). When used in double shutter mode, the camera is capable of acquiring an image pair with a minimum $500 \mathrm{~ns}$ delay between the end of the first gate and the beginning of the second. Each gate has a minimum duration of $20 \mathrm{~ns}$, with delay settings and durations set in increments of $20 \mathrm{~ns}$. A detailed discussion of the timing sequence methodology used in the NO PLIF experiments is provided in Ref. 13.

\section{Temperature Sensitive Paint (TSP) Heat Transfer Measurement System}

The temperature sensitive paint system employed in this study was based on a formulation developed at NASA LaRC and described previously. ${ }^{17}$ The TSP layer is made by dissolving the luminophore ruthenium trisbypyridine (Rubpy) in a commercially available clear urethane sealant that is them applied to the model using conventional spraying techniques. Before application to the model, the SLA Nanoform surface was cleaned and degreased using acetone. After drying, a white acrylic primer was applied to the surface to act as a basecoat to enhance adhesion of the urethane sealant as well as enhance scattering of the luminescence intensity back to the camera. Calibration of the TSP was performed in a laboratory calibration chamber. The TSP formulation displayed adequate sensitivity up to about $420 \mathrm{~K}$, though the luminescence was significantly quenched (less than $1 \%$ of the original signal).

TSP data in the wind tunnel facility was acquired by illuminating the surface with several light emitting diode (LED) arrays. The LEDs that make up the arrays have a center wavelength of $400 \mathrm{~nm}$ with a very narrow emission (approximately $20 \mathrm{~nm}$ full-width at half maximum). Images were collected using a 14-bit thermoelectrically cooled Cooke PCO 2000 interline transfer CCD. The camera has an array size of 2048 x 2048 pixels, though binning was employed to increase the collection efficiency (image sizes are 1024 x 1024 pixels). Optical filters were placed in front of the camera lens to discriminate between the luminescence of the TSP and excitation and background light. A reference image for each run was acquired by injecting the model into the test section before tunnel operation. The model was then retracted into the model box, and the tunnel started. Once tunnel conditions stabilized, the model was re-injected and data collection began. TSP images were acquired every 500 ms throughout the run, lasting approximately 5-7 seconds while the model was in the tunnel on centerline. The ratio between the run image and the calibration image was calculated. These ratioed TSP images were then converted to temperature which was used to calculate the convective heat transfer coefficient, as detailed previously. ${ }^{17}$ Because an exact value for the substrate thermal product was unknown for the SLA Nanoform material, the heating results are presented as a ratio of the convective heat transfer coefficient to the convective heat transfer coefficient using the method of Fay and Riddell, $\mathrm{C}_{\mathrm{h}} / \mathrm{C}_{\mathrm{hFR}}$, multiplied by the thermal product ratio, $\beta_{\mathrm{REF}} / \beta$, to acknowledge a factor of error. The TSP heating 
maps have been normalized to the Fay-Riddell stagnation point heating value (the heating rate that would have occurred at the stagnation point of a hemisphere at these same conditions, according to theory of Fay and Riddell). ${ }^{18}$

\section{A. Initial Image Processing}

\section{Image Processing and Analysis}

The spatial resolution for the NO PLIF experiments was measured by acquiring an image consisting of a matrix of square marks separated at equal spatial intervals, known as a dotcard and described in Ref. 19. When these spatial calibration images were acquired, the dotcard was placed in the plane of the laser sheet. The spatial resolution for Runs 15, 17, and 18 of Test 462 was $15.7 \pm 0.04$ pixels $/ \mathrm{mm}$. For Runs 25, 26, and 27 of Test 462, the spatial resolution was $17.5 \pm 0.01$ pixels $/ \mathrm{mm}$. For Runs 3 and 4 of Test 467 , the spatial resolution was $16.7 \pm 0.04$ pixels $/ \mathrm{mm}$.

To correct for optical and perspective distortion of the images, the image of the dotcard in the test section was acquired with the camera and a corresponding undistorted image of the same dotcard was created. An image registration algorithm, UnwarpJ ${ }^{20}{ }^{2}$ was then used to correct the distortion. This software is a plug-in created for the image processing software, ImageJ, a freeware image processing program available from National Institutes of Health. ${ }^{21}$

The approximate streamwise and wall-normal spatial resolutions of the velocity measurement for Runs 15 and 18 of Test 462 were $1.45-\mathrm{mm}$ and $0.07-\mathrm{mm}$, respectively. For Run 17 of Test 462 , the images were binned by 8 pixels in the vertical direction during acquisition of the images, with no other subsequent filtering applied. This reduced the vertical imaging system spatial resolution to approximately $0.56-\mathrm{mm}$.

To improve the signal-to-noise ratio in all plan-view runs in Test 462, MATLAB ${ }^{\circledR}$ was used to apply a 4-pixel radius average disk filter to the undelayed and delayed fluorescence images. The images were then binned by 4 pixels in the spanwise direction. These two steps improved the signal-to-noise by smoothing camera noise and consolidating the signal in regions tagged by the laser. This provided for approximate streamwise and spanwise imaging system spatial resolutions of $1.28-\mathrm{mm}$ and $0.69-\mathrm{mm}$, respectively, for Runs 25,26 , and 27 of Test 462 .

For BLT DTO experiments, consisting of Runs 3 and 4 of Test 467, both the 4-pixel radius disk filter and 4-pixel spanwise binning was applied to all images. This was in addition to binning all of the images by 2 pixels in the vertical direction within the camera hardware. Thus, the approximate streamwise and spanwise imaging system spatial resolutions were $1.54-\mathrm{mm}$ and $0.96-\mathrm{mm}$, respectively.

Prior to processing each image for velocity information, a background offset level was subtracted from the undelayed and delayed images. The background level was obtained from images taken with the laser blocked. Due to the shortness of the gate delay used between the end of the undelayed and the beginning of the delayed images (500 ns) and the relatively long decay time of the P46 phosphor in the intensifier, some ghosting remained from the undelayed image in the delayed image. For the $500 \mathrm{~ns}$ gate delay, this level was experimentally determined to be approximately $1 / 126^{\text {th }}$ of the undelayed image. ${ }^{13}$ Therefore, this fraction of the undelayed image was also subtracted from the delayed image in addition to the normal background offset level. Care was taken over the course of the experiment to avoid saturation of the CCD signal.

\section{B. Velocity and Uncertainty Analysis}

A detailed description of how the velocity and associated uncertainty is computed from the processed images is provided in Ref. 13. However, three modifications have been made to the velocity and uncertainty processing analysis and are worth discussing here.

The first modification to the analysis consisted of a method to obtain a refined estimate of the horizontal spatial shift, $\Delta x$, observed between the undelayed and delayed images. Previous velocity measurements reported (Ref. 13) were made using a fixed-size, fixed-location correlation window. However, for large measured velocities, the potential for truncating the right edge of the delayed profile existed. To minimize the potential for this truncation error, the correlation window was shifted in the delayed image. This was accomplished by first performing a 1dimensional cross-correlation for a 45-pixel-wide window centered about a tagged profile at a particular vertical pixel location in both the undelayed and delayed images. The correlation window in the delayed image was then shifted by an integral number of pixels corresponding to the first estimate obtained in the initial cross-correlation. The cross-correlation was then repeated with the unshifted and shifted windows in the undelayed and delayed frames, respectively, and a final value for the spatial shift was obtained. For image sets with relatively high signalto-noise, the average resulting change in measured velocity due to this procedure is on the order of $5 \%$.

The second modification to the analysis related to the way the spanwise velocity uncertainty is estimated in planview axial velocity measurements. The motivation for the current modification to the spanwise velocity uncertainty calculation is to obtain an improved, point-wise estimation of this value based upon conservation of energy 
principles. Previously a maximum spanwise velocity error was computed by estimating the root difference between the squared maximum and minimum velocities measured along a given profile. Presently this estimate has been refined, using a conservation of energy argument, to estimate the spanwise velocity error as the square root of the difference between the squares of the maximum velocity the gas could have and the measured axial velocity at each location along a profile.

The final modification to the analysis concerns the estimate of the velocity accuracy. Recent unpublished analysis of near-zero velocity wind tunnel data provides an estimate of the measurement accuracy to be $\pm 10 \mathrm{~m} / \mathrm{s}$.

\section{Results and Discussion}

\section{A. Centerline Side-View Velocity Measurements}

Figure 1 shows the average axial centerline velocities measured. Figures $1 \mathrm{a}$ and $1 \mathrm{~b}$ show the results of an unperturbed flat plate measurement at two different unit Reynolds numbers, $1.7 \times 10^{6} \mathrm{~m}^{-1}$ and $3.3 \times 10^{6} \mathrm{~m}^{-1}$, respectively. Figure 1c shows a tripped boundary layer flow at a unit Reynolds number of $1.7 \times 10^{6} \mathrm{~m}^{-1}$. The trip in Figure $1 \mathrm{c}$ is a $2-\mathrm{mm}$ tall by $4-\mathrm{mm}$ diameter cylindrical trip.

The figures show an axis that represents a linear velocity scale, ranging from 0 to $1300 \mathrm{~m} / \mathrm{s}$, which is the same for each measurement. The measurement position is denoted in each figure and represents the location of the measurements with respect to the leading edge of the wedge model. The direction of flow in these figures is from left to right. The lower horizontal axis represents streamwise location relative to the leading edge of the model. The continuous light gray line emanating from the bottom right-hand corner of each figure represents the location of the flat plate surface. This line is not precisely parallel to the data's domain because the camera array and the flat plate were not perfectly aligned in the experiment. In Fig. 1c, the cylindrical trip is represented by the gray shaded rectangle. The velocity points themselves are represented by black rectangles whose center position and width, in relation to the velocity axis, represent the mean velocity and velocity uncertainty, respectively, at that point.

In all the velocity profiles shown in Fig. 1a, with the exception of the first and second profiles, a parabolic-like velocity distribution is observed, as expected. The minimum uncertainty encountered among all of the profiles is $22.6 \mathrm{~m} / \mathrm{s}$. These profiles terminate at the boundary layer edge, attaining a velocity of approximately $1300 \mathrm{~m} / \mathrm{s}$. An inviscid oblique shock calculation places the edge velocity at $1389 \mathrm{~m} / \mathrm{s}$, which is probably an overestimate since viscous interaction has been ignored in this computation. The measurement points nearest to the edge of the boundary layer exhibit larger uncertainties due to reduced and/or intermittent signal levels near the boundary layer edge. This is thought to be a result of either unsteadiness in the seeding and entrainment of NO gas into the boundary layer from the seeding slot, small facility-based acoustic disturbances, or some combination of the two. As the profiles approach the wall boundary, they appear to trend towards zero, satisfying the no-slip wall boundary condition. However, close inspection of each of the profile's data points nearest to the wall reveals that, in most cases, a finite velocity component has been measured. These points have been denoted by lightly shaded gray rectangles, as they are thought to represent unphysical measurements. The cause of this non-physicality can be attributed, in part, to scatter of the laser light off of the model surface in the undelayed image. In the delayed image, near the location of this scatter, it appears that a depletion of available signal in the camera's phosphor screen has occurred. The result of this phenomenon is a false right-weighting of the delayed profiles and consequently non-zero velocities near the wall at these locations. Figure 2 shows a raw image of Run 18 of Test 462 where this consequence of laser scatter can be observed. This estimated maximum extent of this phenomenon off of the surface of the model is $0.38-\mathrm{mm}$.

The first and second velocity profiles in Fig. 1a $(5.15-\mathrm{cm}$ and $5.47-\mathrm{cm}$, respectively) are observed to take on a slightly different shape as compared to the more parabolic-like profiles seen in the remaining measurement space. The first profile, located 5.15-cm downstream of the leading edge, appears to take on the shape of a downturned hockey stick, with a stronger velocity gradient occurring in the lower $1 / 3$ (nearer to the wall boundary) of the data points. Beyond this region, the velocity profile becomes nearly linear, reaching a maximum value of $1181 \mathrm{~m} / \mathrm{s}$. Although less pronounced, the second profile exhibits similar behavior, reaching a maximum value of $1193 \mathrm{~m} / \mathrm{s}$ farthest from the wall. In both cases, the velocity near the upper edge of the measured profile does not appear to blend in to the estimated boundary layer edge velocity condition of $1389 \mathrm{~m} / \mathrm{s}$. In these cases, it is possible that the NO, which has been seeded into the boundary layer well downstream of the leading edge of the flat plate, has not yet reached the edge of the boundary layer as defined by the velocity-profile. Further downstream, the NO diffuses to and perhaps beyond the edge of the velocity profile's boundary layer since mass diffusion of NO in air is most likely faster than viscous diffusion in the boundary layer. Calculation of the Schmidt number over a representative temperature field within the boundary layer supports this assertion. 


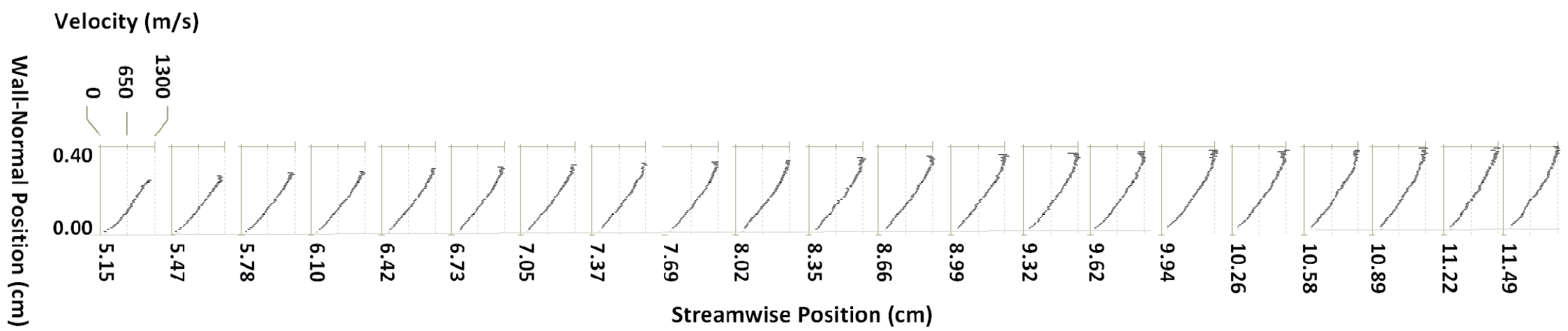

(a)

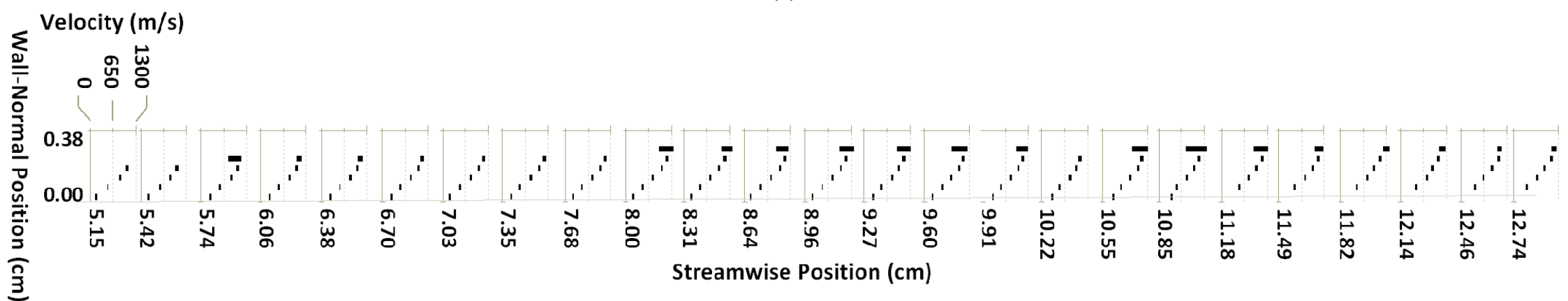

(b)
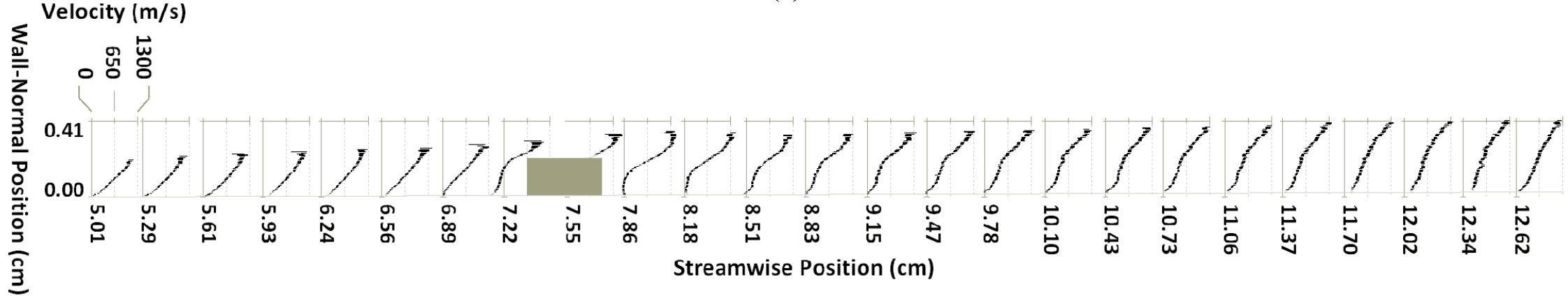

(c)

Fig. 1 Centerline mean velocity with no trip (a) and (b) for $\operatorname{Re}_{\mathrm{x}}=1.7 \times 10^{6} \mathrm{~m}^{-1}$ and $3.3 \times 10^{6} \mathrm{~m}^{-1}$, respectively. Centerline velocity with cylindrical trip (c) for $\operatorname{Re}_{\mathrm{x}}=1.7 \times 10^{6} \mathrm{~m}^{-1}$. The cylindrical trip in (c) represented by gray shaded area. Estimated uncertainty in laser sheet position is $\pm 0.5 \mathrm{~mm}$. Images (a), (b), and (c) correspond to Runs 15,17 , and 18 of Test 462, respectively. 
Figure $1 \mathrm{~b}$ shows the velocity measurements for the no-trip, $3.3 \times 10^{6} \mathrm{~m}^{-1}$ unit Reynolds number case. The reduced number of data points is a consequence of the 8-pixel camera binning. For this data set, it appears that each of the data profiles, although sparse, take on a laminar parabolic-like profile, as expected. As with the lower unit Reynolds number case in Fig. 1a, some of the data points farthest from the wall boundary have larger uncertainties with respect to the remainder of the data points. It should be noted that the data points farthest from the wall boundary presented are not necessarily located at the velocity boundary layer edge. In some instances near the edge of the boundary layer, velocity points have been removed due to relatively large uncertainties, some exceeding $\pm 500 \mathrm{~m} / \mathrm{s}$. The minimum uncertainty encountered among all profiles for this run was approximately $23 \mathrm{~m} / \mathrm{s}$.

Figure $1 \mathrm{c}$ shows the resulting velocity profiles at a unit Reynolds number of $1.7 \times 10^{6} \mathrm{~m}^{-1}$ with the 2-mm tall by $4-$ $\mathrm{mm}$ diameter cylindrical trip. In this figure, profiles 2 through $6(5.29-\mathrm{cm}$ through $6.56-\mathrm{cm}$, respectively) take on the expected parabolic-like velocity distributions. Along the $7^{\text {th }}$ profile $(6.89-\mathrm{cm})$, as the flow approaches the cylindrical trip, an inflection point forms very near the wall boundary while the upper portion of the profile maintains its parabolic-like shape. However, the mean velocity along this profile appears to have uniformly decreased when compared to the $6^{\text {th }}$ profile $(6.56-\mathrm{cm})$ at the same vertical station. For the $8^{\text {th }}$ profile (immediately in front of the trip at $7.22-\mathrm{cm}$ ), a reversal in flow direction extending nearly to the height of the tripping element is observed, indicating a large separated flow region forward of the trip. For the same profile, in the region extending above the trip height, it appears that a strong velocity gradient develops (compared to previous profiles). The mean velocity in this region has uniformly decreased when compared to the $7^{\text {th }}$ profile $(7.22-\mathrm{cm})$ at the same vertical station. As noted above, it appears some magnitude of velocity slip occurs at the wall boundary, in the upstream direction. However, examination of Fig. 2 does not provide conclusive evidence of slip when camera laser scatter and/or phosphor depletion effects are taken into account. As the boundary layer gas passes over the tripping element, the $9^{\text {th }}$ profile $(7.55-\mathrm{cm})$ indicates that the flow is accelerated while maintaining a steep velocity gradient. Again, it appears that some level of velocity slip (this time in the downstream direction) occurs at the trip surface, which is thought to be a result of laser scatter.

The $10^{\text {th }}$ profile (immediately downstream of the cylindrical trip and located 7.86-cm downstream of the leading edge), exhibits near-zero axial flow extending from the wall boundary to approximately $1-\mathrm{mm}$ in the wall-normal direction. Beyond this height, the velocity increases in a parabolic-like fashion to the edge velocity condition at approximately $3.3-\mathrm{mm}$ normal to the wall. The next $\left(11^{\text {th }}\right)$ profile, located $8.18 \mathrm{~cm}$ from the leading edge, exhibits similar behavior; however, a relatively small linear increase in velocity extending from the wall boundary to approximately $1-\mathrm{mm}$ in the wall normal direction is observed. Beyond this point, the velocity profile again takes on a parabolic-like shape $(8.51-\mathrm{cm}$ through $12.62-\mathrm{cm}$, respectively). For each profile downstream of the trip, the region extending from the wall boundary to 1-mm off of the plate surface exhibits a velocity deficit relative to the flow upstream of the trip. However, the velocity gradient becomes more uniformly linear (except for a slightly larger gradient very near the wall boundary) with each successive profile, indicating that the flow in this velocity-deficit region is accelerating slowly in the streamwise direction. The minimum uncertainty encountered among the mean profiles for this run was approximately $24 \mathrm{~m} / \mathrm{s}$.

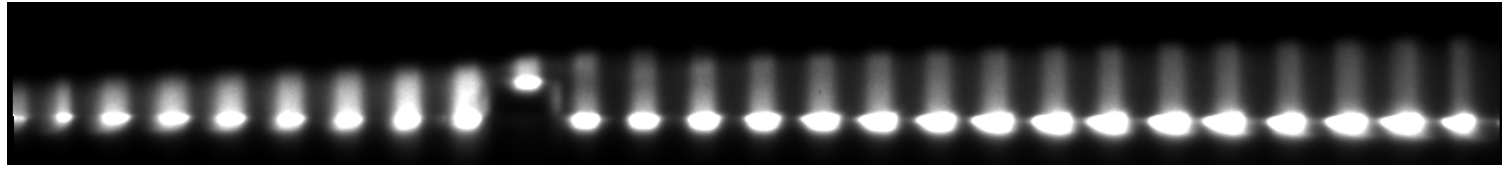

(a)

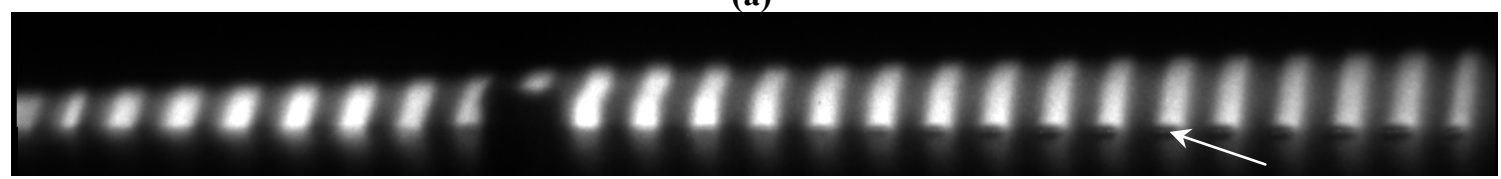

(b)

Fig. 2 Averaged centerline (a) undelayed and (b) delayed raw velocity images for $\operatorname{Re}_{\mathrm{x}}$ of $1.7 \times 10^{6} \mathrm{~m}^{-1}$ with a 2-mm tall, 4-mm diameter cylindrical trip. Measurements are from Run 18 of Test 462. The phosphor depletion effect is especially noticeable in the bottom right of (b) where an arrow shows a depleted region corresponding to a very bright region in (a).

\section{B. Plan-View Velocity Measurements}

Figures $3 \mathrm{a}$ through $3 \mathrm{~d}$ represent the no-trip, plan-view laminar boundary layer velocity measurements for the $1.7 \times 10^{6} \mathrm{~m}^{-1}$ unit Reynolds number case. The respective off-wall positions of the measurements are $0.4-\mathrm{mm}, 0.5-\mathrm{mm}$, $1.7-\mathrm{mm}$, and 2.6- $\mathrm{mm}$ with an estimated position uncertainty of $\pm 0.5-\mathrm{mm}$. In Fig. 3a, the measurement closest to the wall boundary, the mean velocities are on the order of $100 \mathrm{~m} / \mathrm{s}$ to $400 \mathrm{~m} / \mathrm{s}$. Due to the close proximity of the measurement plane to the flat plate surface (the laser sheet has a finite thickness), the relatively large uncertainties 
encountered are attributed to mechanical vibrations affecting the laser sheet position which, in some instances, resulted in a portion of the laser sheet being blocked by the model. These large uncertainties are also attributed to scatter from the laser across the surface, which affects the cross-correlation results. The minimum uncertainty observed at this position is $34 \mathrm{~m} / \mathrm{s}$, with the mean uncertainty being $86 \mathrm{~m} / \mathrm{s}$. In general, these profiles appear to be uniformly linear within the confines of the experimental uncertainty.

In Fig. 3b, the measurement plane has been positioned slightly farther $(0.5 \mathrm{~mm})$ off of the plate surface, resulting in greatly reduced experimental uncertainty across all of the velocity profiles. The minimum uncertainty encountered at this position is $20 \mathrm{~m} / \mathrm{s}$, with a mean uncertainty of $28 \mathrm{~m} / \mathrm{s}$. The uniformly linear velocity profile behavior seen in this figure is expected for this unperturbed laminar flow. Figure $3 \mathrm{c}$ shows the velocity profiles for a measurement plane positioned even higher $(1.7 \mathrm{~mm})$ off of the plate surface. Mean velocities across this plane are on the order of $796 \mathrm{~m} / \mathrm{s}$ with a standard deviation of $57 \mathrm{~m} / \mathrm{s}$. Again, the profiles exhibit a uniformly linear velocity behavior with relatively small uncertainties, indicating that very little flow unsteadiness exists within the boundary layer at this wall-normal position. The minimum uncertainty observed at this position is $27 \mathrm{~m} / \mathrm{s}$, with a mean uncertainty of $36 \mathrm{~m} / \mathrm{s}$. Figure $3 \mathrm{~d}$ shows the velocity profiles measured at 2.6- $\mathrm{mm}$ off of the plate surface. While the profiles located at and beyond 7.95-cm downstream of the model's leading edge exhibit the same uniformly linear velocity behavior with relatively low uncertainty, profiles upstream of this location exhibit increased uncertainties. This increase in uncertainty is due to the measurement plane intersecting near, at, or above the edge of the boundary layer marked by $\mathrm{NO}$, resulting in intermittent fluorescence signal.

Figures $4 \mathrm{a}$ through $4 \mathrm{c}$ show the tripped, plan-view boundary layer velocity measurements for the $1.7 \times 10^{6} \mathrm{~m}^{-1}$ unit Reynolds number case. The respective off-wall positions of the measurements are $0.3 \mathrm{~mm}, 2.1 \mathrm{~mm}$, and $3.1 \mathrm{~mm}$ with an estimated position uncertainty of $\pm 0.5-\mathrm{mm}$. The position of the 2-mm tall, 4-mm diameter cylindrical trip is outlined by a light gray boundary in each figure. In Fig. 4a, the first three profiles $(6.46-\mathrm{cm}$ through $6.88-\mathrm{cm}$, respectively) exhibit uniformly linear velocity behavior. Again, a slight increase in uncertainty along all profiles is observed due to laser sheet cut off and surface scatter. At 7.09-cm and 7.31-cm downstream of the leading edge, the bowing of the velocity profiles indicates that the trip is beginning to influence the upstream flow, resulting in reduced, and even negative, centerline velocities of $127 \mathrm{~m} / \mathrm{s}$ and $-272 \mathrm{~m} / \mathrm{s}$, respectively. Downstream of the trip and along the centerline of the model, a slight velocity deficit is observed for each profile. Additionally, each of these profiles exhibits regions of streamwise flow acceleration extending downstream from the spanwise edges of the trip. The prominence of these post-trip velocity profile curvature features gradually diminishes with increasing downstream distance. The velocity profiles shown in Fig. 4b, while occurring farther off the surface of the plate, exhibit the same general behavior. For the profile just in front of the trip $(7.31-\mathrm{cm})$, the velocity deficit along the centerline has increased with respect to the linear flow portions along the same profile while the centerline value has increased to $97 \mathrm{~m} / \mathrm{s}$. This indicates the location of a nearly stagnant region just ahead of the trip. Figure $4 \mathrm{~b}$ shows that the curvature of the velocity profiles at each downstream location is increasing slightly with increased downstream distance, unlike Fig. 4a, where the wake disturbance smoothes out with increasing distance downstream. In Fig. 4c, along the first six velocity profiles $(6.46-\mathrm{cm}$ through $7.52-\mathrm{cm}$, respectively), the laser sheet position is either at or above the edge of the boundary layer, resulting in low signal and large measurement errors. In profiles 7 through $13(7.74-\mathrm{cm}$ through $9.04-\mathrm{cm}$, respectively), the velocity behavior appears to be minimally affected by the presence of the tripping element. For the remainder of the downstream profiles $(9.25$-cm through $11.86-\mathrm{cm}$ ), curvature behavior similar to that observed in the lower regions of the boundary layer develops with increasing downstream distance. In general, one of the more interesting aspects of Figs. 4a through $4 \mathrm{c}$ is the relatively large velocity gradients that exist in the wall-normal direction, extending downstream from the spanwise edges of the trip, very near the plate surface. Observation of the velocity profiles along the centerline of the model downstream of the trip indicates relatively small velocity gradients existing in the wall-normal direction. Thus, if only centerline wall-normal velocity profiles had been obtained, some of the steepest gradients would not have been observed.

Figure 5a through $5 \mathrm{~d}$ shows the results of the tripped flow measurement at the $3.3 \times 10^{6} \mathrm{~m}^{-1}$ unit Reynolds number condition. This case, also expected to be laminar, was tested primarily to probe the limits of the MTV measurement technique. The respective off-wall positions of the measurements are $0.2-\mathrm{mm}, 0.6-\mathrm{mm}, 1.7-\mathrm{mm}$, and $2.7-\mathrm{mm}$ with an estimated position uncertainty of $\pm 0.5-\mathrm{mm}$. The position of the 2-mm tall, 4-mm diameter cylindrical trip is outlined by a light gray boundary in each figure. Again in Figs. 5a and 5b, a slight increase in uncertainty along all profiles is observed due to laser sheet cut off and surface scatter. In Fig. 5a, it can be observed that profiles downstream of the tripping element exhibit increased curvature, and hence stronger velocity gradients, in the wake and near-wake region. In subsequent off-body measurement plane locations, such as in Figs. $5 \mathrm{~b}$ and $5 \mathrm{c}$, the same large profile curvature trend can be observed. In Fig. 5d, the wake and near-wake region of the tripping element exhibits a gradual increase in profile curvature as downstream distance is increased. As in the tripped lower unit Reynolds 
Velocity (m/s)

ㅇํㅇํํำ

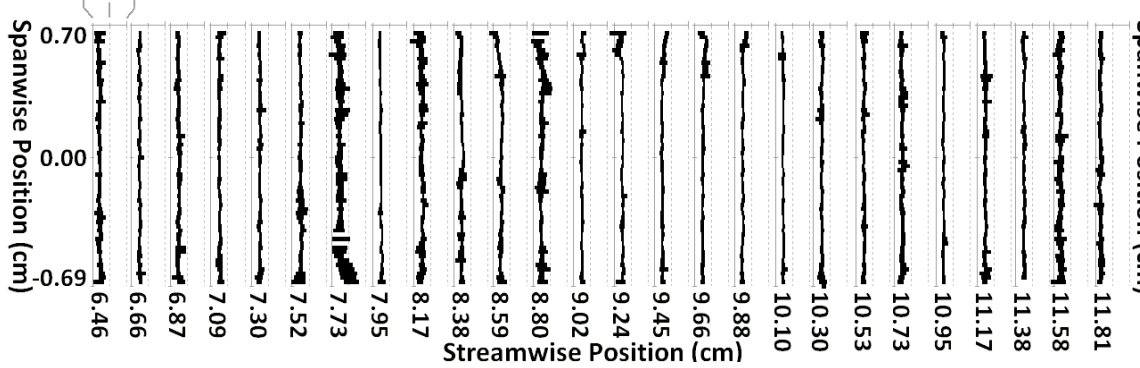

(a)

Velocity $(\mathrm{m} / \mathrm{s})$

ஸิँ

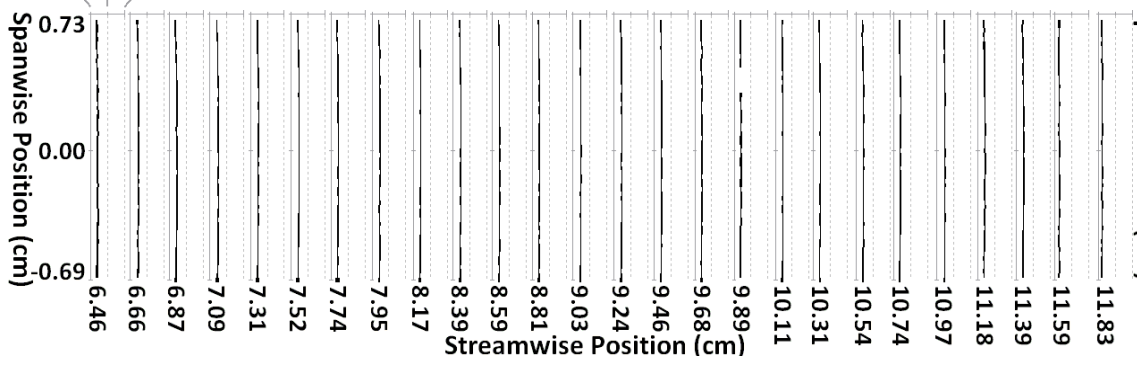

(b)

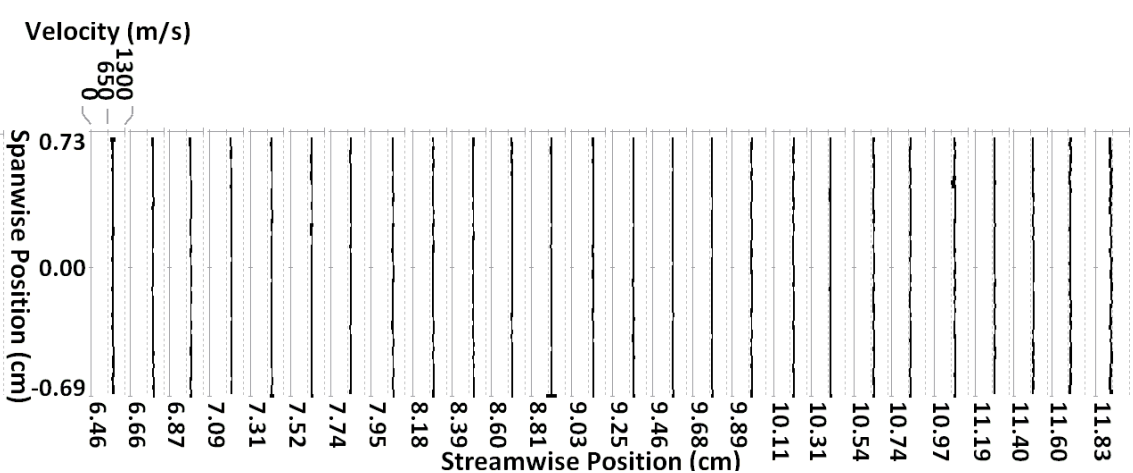

(c)

Velocity $(\mathrm{m} / \mathrm{s})$

ஸัँे

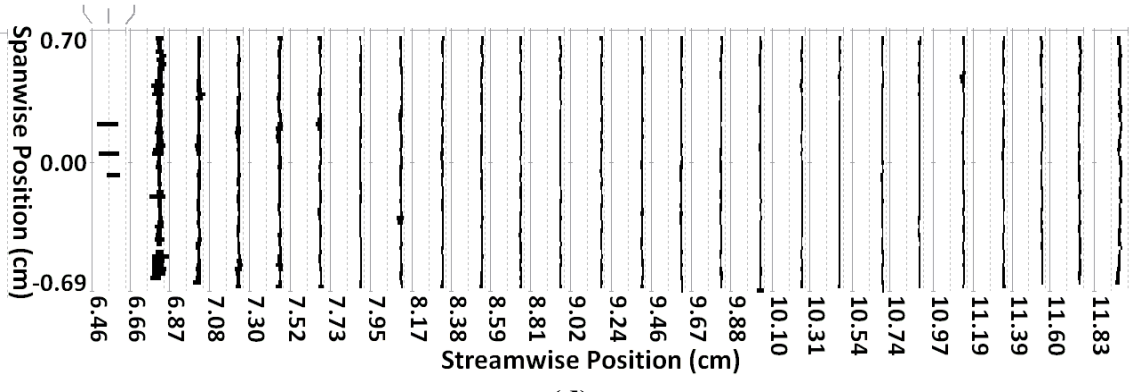

(d)

Fig. 3 Plan-view mean velocity profiles with no trip for $R_{x}=1.7 \times 10^{6} \mathrm{~m}^{-1}$ at off-body positions of (a) $0.4-\mathrm{mm}$, (b) $0.5-\mathrm{mm}$, (c) $1.7-\mathrm{mm}$, and (d) $2.6-\mathrm{mm}$. Estimated uncertainty in laser sheet position is $\pm 0.5 \mathbf{m m}$. Images from Run 27 of Test 462. 


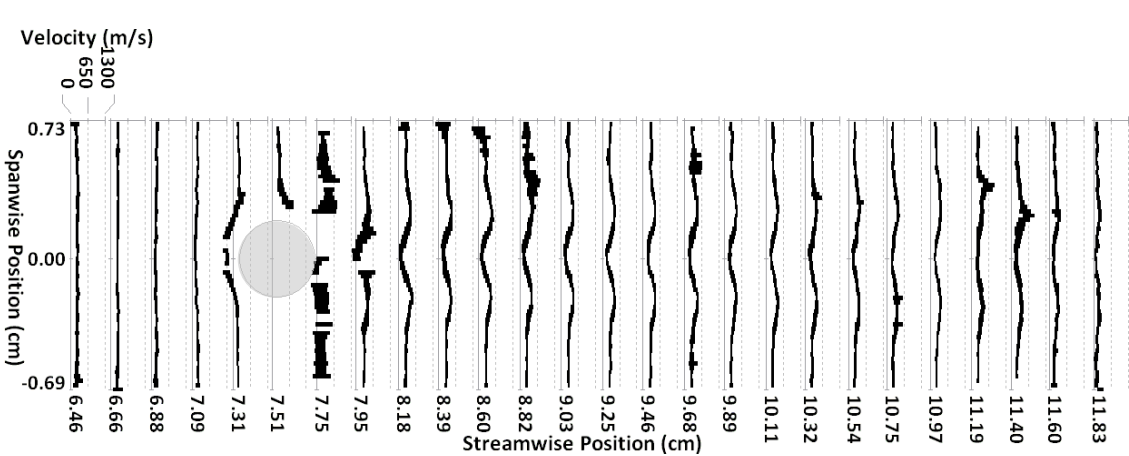

(a)
Velocity $(\mathrm{m} / \mathrm{s})$

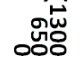

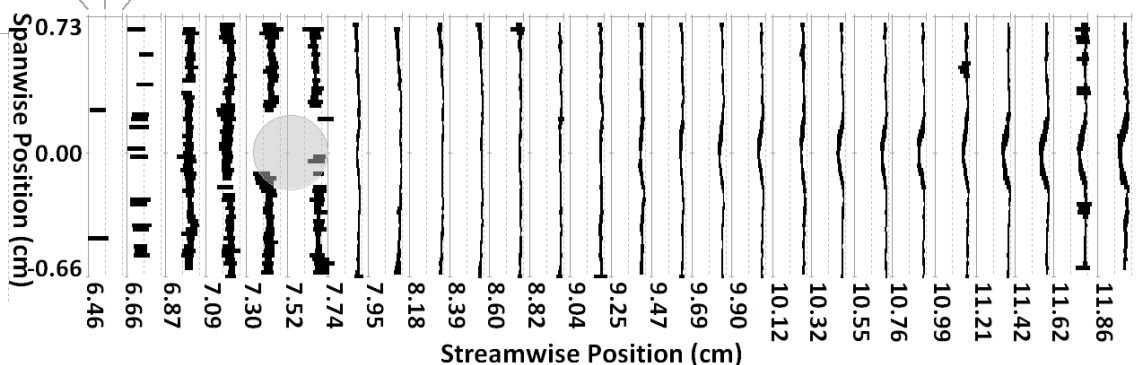

(c)

Velocity $(\mathrm{m} / \mathrm{s})$

닝

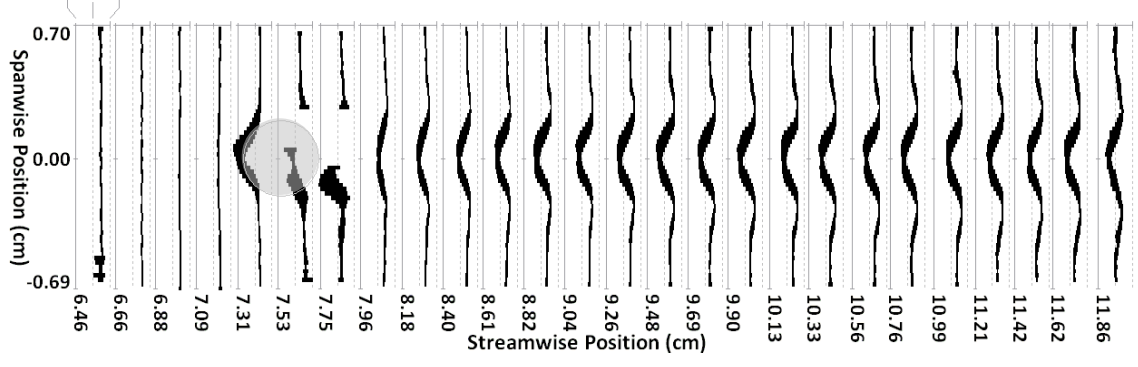

(b)

Fig. 4 Plan-view mean velocity profiles with $2-\mathrm{mm}$ tall, 4-mm diameter cylindrical trip for $\operatorname{Re}_{\mathrm{x}}=1.7 \times 10^{6} \mathrm{~m}^{-1}$ at off-body positions of (a) $0.3-\mathrm{mm}$, (b) $2.1-$ $\mathrm{mm}$, and (c) 3.1-mm. Estimated uncertainty in laser sheet position is $\pm 0.5 \mathrm{~mm}$. Images from Run 25 of Test 462. 

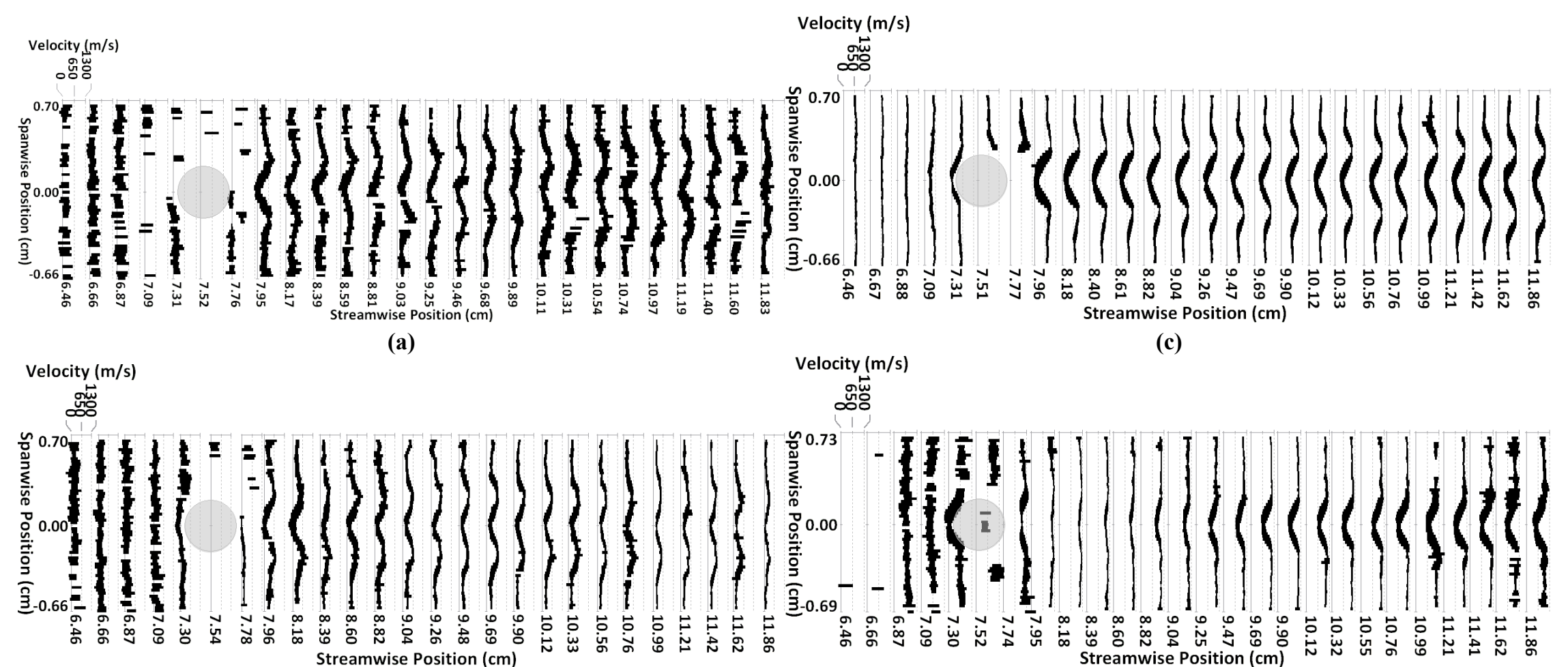

(b)

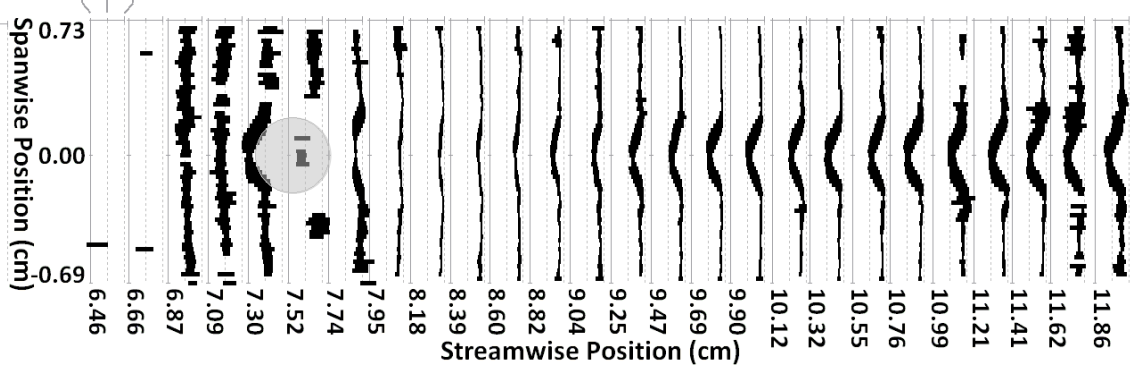

(d)

Fig. 5 Plan-view mean velocity profiles with 2 -mm tall, 4-mm diameter cylindrical trip for $\operatorname{Re}_{\mathrm{x}}=3.3 \times 10^{6} \mathrm{~m}^{-1}$ at off-body positions of (a) 0.2 -mm, (b) 0.6 $\mathrm{mm}$, (c) $1.7-\mathrm{mm}$, and (d) 2.7-mm. Estimated uncertainty in laser sheet position is $\pm 0.5 \mathrm{~mm}$. Images from Run 26 of Test 462. 
number case presented in Fig. 4, it appears as though an even stronger velocity gradient exists in the wall-normal direction, extending downstream from the spanwise edges of the trip, very near the plate surface. Also similar to what was observed in Fig. 4, a relatively small velocity gradient in the wall normal direction appears to exist along the centerline of model. Comparison of the plan view centerline velocities in Fig. 4 and 5 with the centerline velocities measured in Fig. 1c confirms that a relatively weak velocity gradient exists downstream of the tripping element along the centerline.

\section{Temperature Sensitive Paint (TSP) Surface Measurements}

Figures $6 \mathrm{a}$ through $6 \mathrm{~d}$ shows the results of TSP measurements. Note that the white circles indicate regions where no heat transfer data was acquired and correspond to the 8-mm outer diameter of the insert onto which the 4-mm diameter trip was machined. The trip was centered on the insert, as indicated by the smaller inner circles. For the no-trip case with a unit Reynolds number of $1.7 \times 10^{6} \mathrm{~m}^{-1}$ in Fig. $6 \mathrm{a}$, it can be seen that a relatively uniform heat transfer distribution exists across the insert surface. This heat transfer image corresponds to the velocity measurements shown in Fig. 1a and Fig. 3.

Figure $6 \mathrm{~b}$ shows the tripped case performed at the same unit Reynolds number condition as in Fig. 6a. This heat transfer image corresponds to the velocity measurements shown in Fig. 1c and Fig. 4. Of interest is the wake region downstream of the tripping element. Beginning immediately behind the spanwise edges of the trip, a two-streak pattern of increased heat transfer develops. These streaks are broadest approximately 2 trip diameters downstream of the center of the trip, widening to approximately $2 / 3$ of the trip diameter. Beyond this point, the streaks slowly narrow and exhibit reduced heat transfer to the surface with increasing downstream distance. The outer boundary of this heat transfer pattern (farthest from the model centerline) maintains a relatively sharp edge downstream of the trip. Along the centerline, no noticeable increase in heat transfer is observed, coinciding with the velocity deficits observed in the corresponding velocity measurement figures. As expected, the region over which increased heat transfer is observed corresponds to the regions of relatively large velocity gradients in the wall-normal direction. This also corresponds to where the velocity accelerates downstream of the spanwise edges of the trip.

Figure $6 \mathrm{c}$ shows the tripped case performed at the $3.3 \times 10^{6} \mathrm{~m}^{-1}$ unit Reynolds number condition, corresponding to

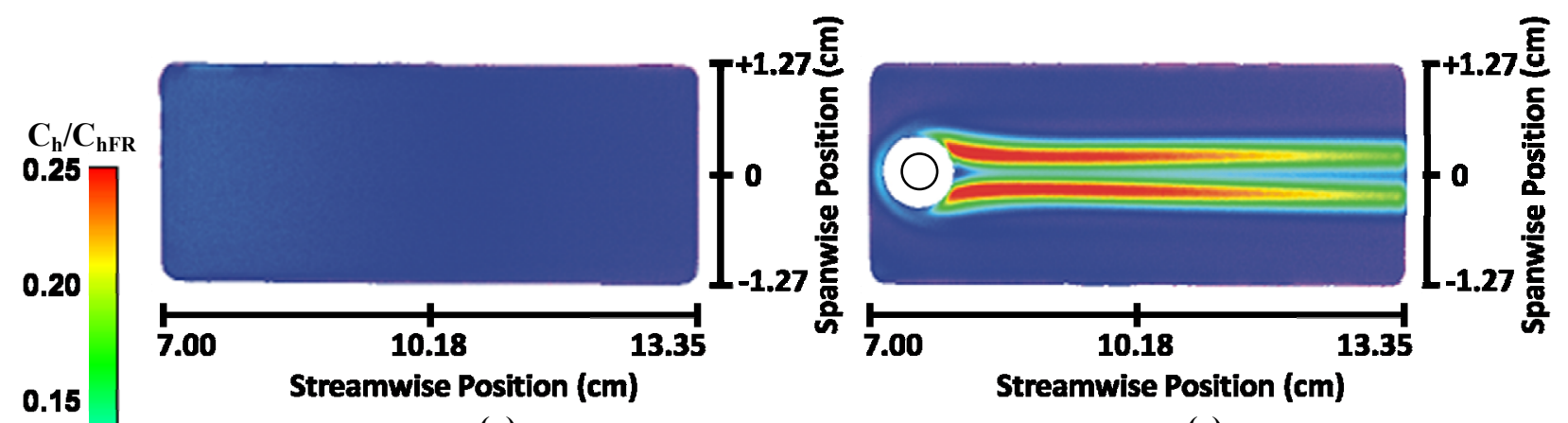

(a)

(c)

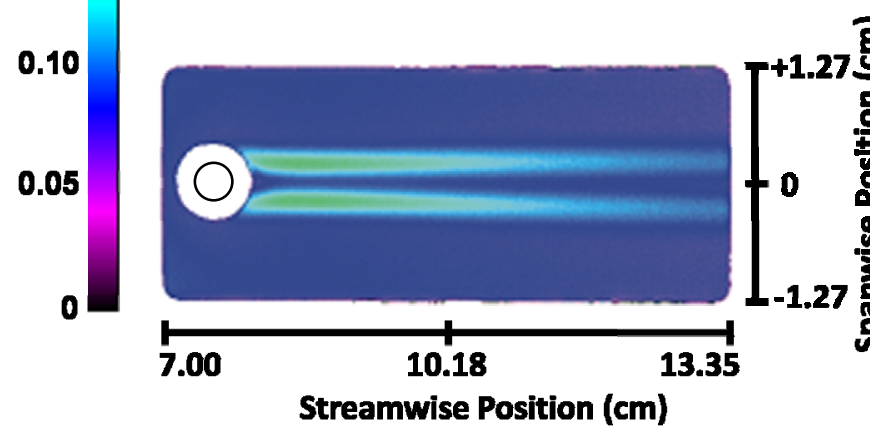

(b)

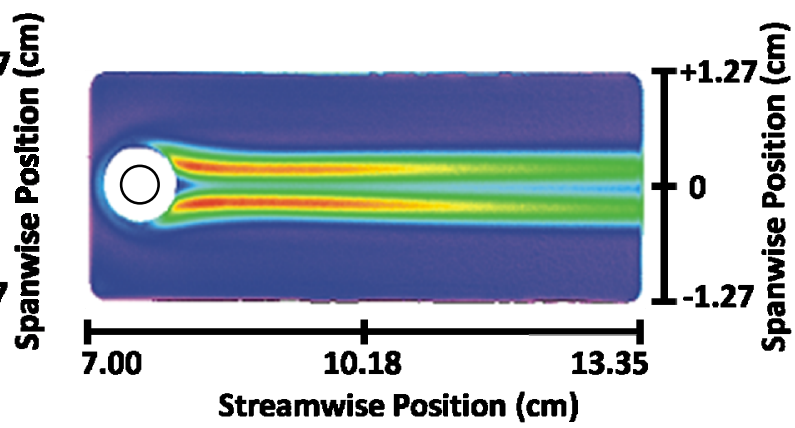

(d)

Fig. 6 TSP heat transfer images for $\operatorname{Re}_{\mathrm{x}}=$ (a) $1.7 \times 10^{6} \mathrm{~m}^{-1}$ with no trip, (b) $1.7 \times 10^{6} \mathrm{~m}^{-1}$ with trip, (c) $3.3 \times 10^{6} \mathrm{~m}^{-1}$ with trip, and (d) $3.3 \times 10^{6} \mathrm{~m}^{-1}$ with trip and $300 \mathrm{SCCM} \mathrm{N}_{2}$ gas supplied from seeding slot. Images (a), (b), (c), and (d) from Runs 30, 29, 31, and 33 of Test 462, respectively. Image (a) corresponds to velocity Runs 15 and 27 and of Test 462. Image (b) corresponds to velocity Runs 18 and 25 of Test 462. Images (c) and (d) correspond to Run 26 of Test 462. 
velocity measurements provided in Fig. 5. Unlike the lower unit Reynolds number heat transfer image in Fig. 6b, a bowed region of increased heat transfer wraps around the front edge of the tripping element and extends well beyond the spanwise edges of the trip (and beyond the base of the trip insert), decreasing in intensity to the level of the ambient heat transfer values at approximately 2 trip diameters above and below the center of the trip. At this point, a new heat transfer pattern initiates that is similar, but not identical, to the heating pattern observed in the lower unit Reynolds number case (Fig. 6b). A key difference at this higher unit Reynolds number condition is the drastically higher heat transfer and the associated broadening of the dual streak pattern behind the trip, with the increased heating now penetrating all the way to the centerline for most streamwise positions. As with the lower unit Reynolds number heat transfer image, the increased heat transfer occurs in regions having relatively large velocity gradients in the wall-normal directions. Figure $6 \mathrm{~d}$ shows the heat transfer pattern obtained for the same conditions as in Fig. 6c, except with $300 \mathrm{SCCM}$ of $\mathrm{N}_{2}$ gas seeded through the upstream slot. This heat transfer pattern is qualitatively similar to that predicted in Fig. 11a of Ref. 2 for similar flow conditions. This images shows a very slight difference in heat transfer pattern, which is assumed to negligibly affect the surround boundary layer flow.

Figure 7 shows the combined TSP and velocity data superimposed on a virtual wedge model. Figures $7 \mathrm{a}$ and $7 \mathrm{~b}$ show the resulting TSP images from Runs 29 (Fig. 6b) and 33 (Fig. 6d) of Test 462, respectively. In Figs. 7a and 7b the corresponding plan-view velocity maps are taken from Runs 25 (Fig. 4b) and 26 (Fig. 5c) of Test 462, respectively. Note that the TSP color scale provided in these images varies slight from those in Fig. 6 . The black fringes around the edges of the TSP images correspond to regions on the edge of the TSP coated insert that provided no heat transfer signal. In both images, the regions of increased heat transfer on the TSP maps correspond to the regions of increased velocity downstream of the spanwise edges of the trip. In Fig. 7b, it is interesting to note that along the path of increased heat transfer and accelerated velocity regions between 0 to 2 trip diameters behind the trip, it appears that a significant spanwise velocity component most likely exists in the direction of the centerline. To a smaller extent this might also occur in Fig. 7a. In Figs. 7a and 7b, the approximate wall-normal position of the velocity measurements are at $2.1-\mathrm{mm}$ and $1.7-\mathrm{mm}$, respectively.

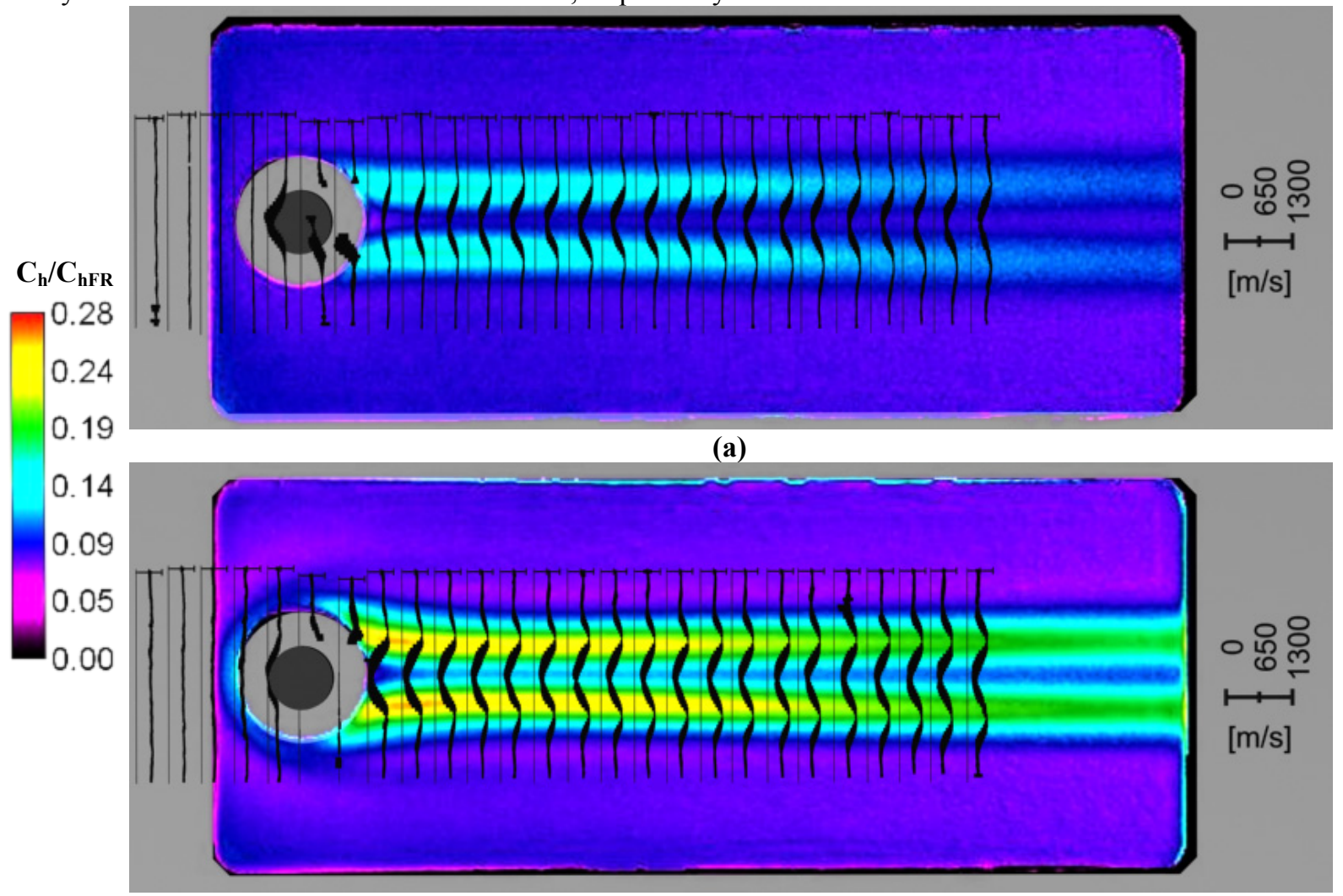

(b)

Fig. 7 TSP heat transfer images with superimposed plan-view axial velocity maps for $\operatorname{Re}_{\mathrm{x}}=$ (a) $1.7 \times 10^{6} \mathrm{~m}^{-1}$ and (b) $3.3 \times 10^{6} \mathrm{~m}^{-1}$. Image (a) corresponds to velocity Runs 25 and 29 and of Test 462. Image (b) corresponds to velocity Runs 26 and 33 of Test 462 . Velocity maps in (a) and (b) correspond to Figs. $4 b$ and $5 c$, respectively. Velocity scale is from 0 to $1300 \mathrm{~m} / \mathrm{s}$. For TSP data, there was no blowing for (a) and $300 \mathrm{SCCM}$ of $\mathrm{N}_{2}$ supplied from seeding slot for TSP data for (b). 


\section{Plan-view BLT DTO Velocity Measurements}

Figures $8 \mathrm{a}$ and $8 \mathrm{~b}$ represent the plan-view laminar boundary layer velocity measurements with a 1-mm tall BLT DTO trip at the $1.7 \times 10^{6} \mathrm{~m}^{-1}$ unit Reynolds number condition. The respective off-wall positions of the measurements are $0.4-\mathrm{mm}$ and $0.9-\mathrm{mm}$ with an estimated position uncertainty of $\pm 0.5 \mathrm{~mm}$. The position of the 1-mm tall BLT DTO trip is outlined by a light gray boundary in each figure. Near the surface (Fig. 8a), the flow appears to be minimally affected by the presence of the trip, probably because the trip is so small compared to the boundary layer thickness $(\mathrm{k} / \delta \approx 0.32)$. Along the profile immediately upstream of the leading edge of the trip, located 7.30 -cm from the leading edge, a slight bowing reduction in the velocity can be observed. However, for all other profiles, both upand downstream, a nearly uniformly linear velocity behavior is observed. In Fig. 8b, the flow again remains essentially undisturbed along the first several profiles. The profile immediately in front of the leading edge of the tripping element, located $7.30-\mathrm{cm}$ from the leading edge, again exhibits a slight bowing in the velocity. As the flow passes around the windward-facing edge of the BLT DTO trip, a linear increase in velocity extending from near the trip's surface outward is observed. This occurs along the profiles located at $7.60-\mathrm{cm}$ and $7.89-\mathrm{cm}$ downstream of the leading edge. On the opposite (leeward) side of the trip for the same profiles, flow acceleration is observed. For the remaining post-trip profiles, beginning with the profile located $8.47-\mathrm{cm}$ downstream of the leading edge, only slight curvatures in the profiles are observed. These curvatures can be observed extending downstream of the two spanwise trip edges, with a gradual reduction in the prominence of curvature with increased downstream distance.

Figures $9 \mathrm{a}$ through $9 \mathrm{~d}$ represent the plan-view laminar boundary layer velocity measurements with a $2.5-\mathrm{mm}$ tall BLT DTO trip at the $1.7 \times 10^{6} \mathrm{~m}^{-1}$ unit Reynolds number condition. The respective off-wall positions of the measurements are $0.8-\mathrm{mm}, 1.1-\mathrm{mm}, 2.3-\mathrm{mm}$, and $3.4-\mathrm{mm}$ with an estimated position uncertainty of $\pm 0.5 \mathrm{~mm}$. The position of the $2.5-\mathrm{mm}$ tall BLT DTO trip is outlined by a light gray boundary in each figure. In Fig. 9a, only the first profile, located 6.46-cm downstream of the leading edge, shows minimal influence from the tripping element. The next three profiles appear to develop slight linear velocity gradients with the minimum velocities for each profile located directly upstream of the leading edge of the trip. As the flow passes around the windward side of the trip, the velocities for profiles located from $7.61-\mathrm{cm}$ to $8.77-\mathrm{cm}$ are uniformly reduced to near-zero. Examination of the raw images indicates the flow is being deflected away from the windward surface of the trip in the spanwise direction in this region. On the opposite (leeward) side of the trip, the limited number of velocity data points is a result of partial blockage of the laser profiles by the tripping element. As the flow passes around the windward side of the trailing edge of the BLT DTO trip, it begins to accelerate in the axial direction. On the opposite side of the trip, the flow still appears to be nearly stagnant with respect to the axial direction. The remaining post-trip velocity profiles again exhibit some level of curvature directly downstream of the spanwise edges of the BLT DTO trip. In Fig. 9b, the same general profile trends are observed, except at uniformly increased velocity. In Fig. 9c, the laser sheet has nearly passed over the top edge of the BLT DTO trip. A relatively large velocity deficit occurs as the flow passes over the apex of the trip, with the velocities on the windward side of the trip being noticeably lower than those on the leeward side. All profiles downstream of the tripping element, located $9.93-\mathrm{cm}$ downstream and beyond, exhibit nearly uniformly linear velocity behavior, with only the region downstream of the spanwise trailing edge developing some level of curvature with increasing downstream distance. In Fig. 9d, the laser sheet is above the tripping element. The only noticeable flow distortion occurs above the tripping element. Curiously, the s-shaped profiles seen downstream of the trip's trailing edge in Fig. 9c are absent here, $1.1 \mathrm{~mm}$ higher in the boundary layer. In general, the profiles in this plane maintain a uniformly linear velocity trend. The increased uncertainties observed near the spanwise fringes of the velocity profiles are attributed to intermittent fluorescence signal.

\section{Discussion}

In retrospect, some observations can be made about the various measurement strategies employed in the experiment. Two different velocity measurement profile laser/camera views were used. In order to make the highest resolution measurements with the least uncertainty in the measurement location, side views are preferable to plan views. This preference over plan views is related to the fact that there is a relatively large uncertainty in the position of the laser sheet perpendicular to the laser sheet. It is undesirable to align this uncertain parameter with a region in the flow having steep velocity gradients. It is best to align this uncertain parameter in spanwise or streamwise direction which have lower gradients then the wall normal direction. Similarly, the thickness of the laser sheet provides spatial averaging over the flow structures, as does the width of each tagged line. These dimensions should be oriented along the smallest gradients in the flow, for example, in the spanwise and streamwise directions, respectively. This was the orientation used, for example in Fig. 1, and is the ideal orientation for providing the highest resolution data for code validation. However, several interesting flow patterns observed in the plan view velocity profiles were not observed in the side-view centerline profiles. So, either both types of measurements 


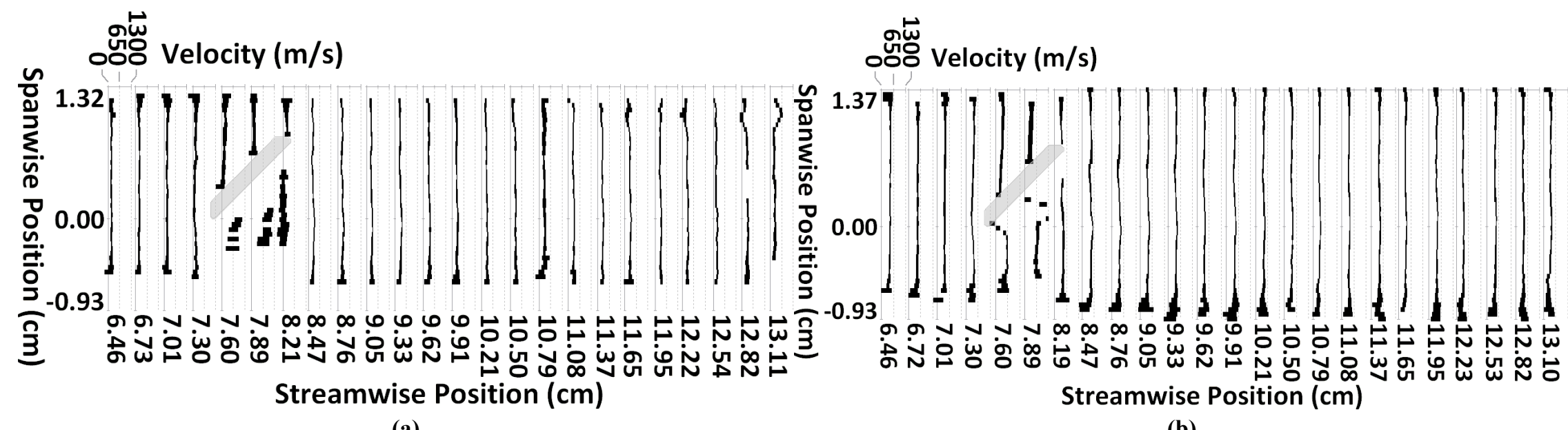

(a)

Fig. 8 Plan-view mean velocity profiles with 1-mm tall BLT DTO trip for $\operatorname{Re}_{\mathrm{x}}=1.7 \times 10^{6} \mathrm{~m}^{-1}$ at off-body positions of (a) 0.4-mm and (b) $0.9-\mathrm{mm}$. Estimated uncertainty in laser sheet position is $\pm 0.2-\mathbf{m m}$. 


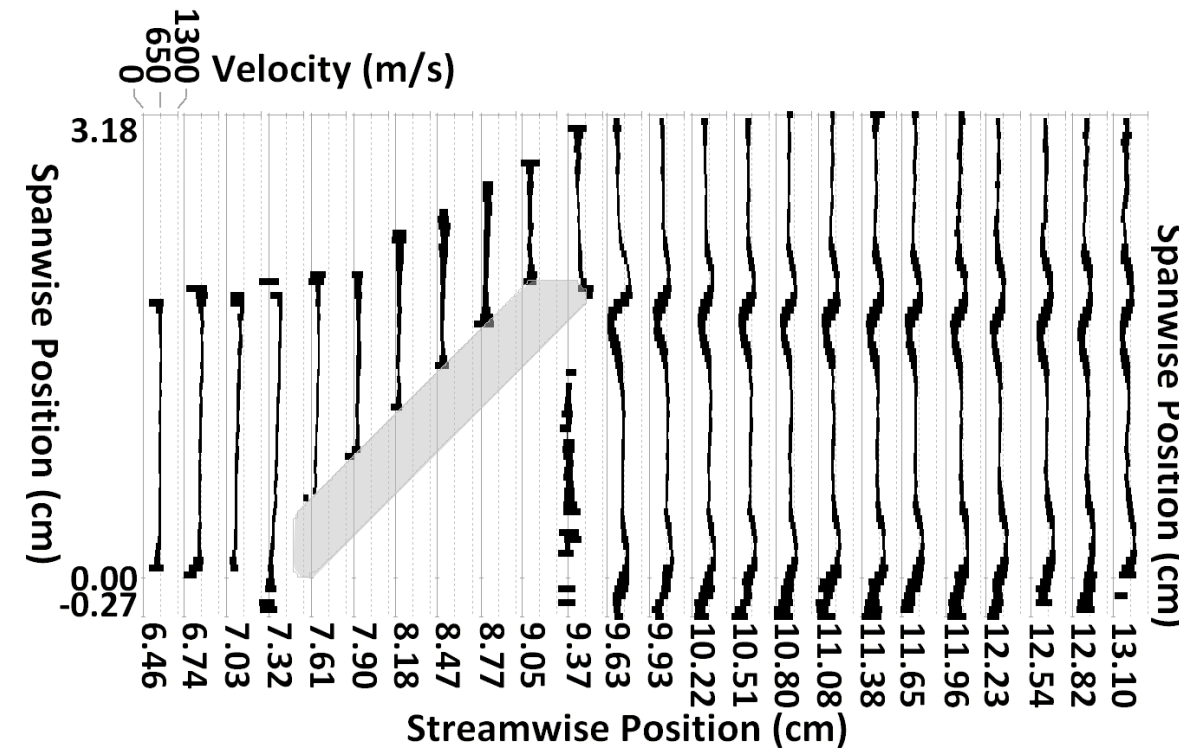

(a)

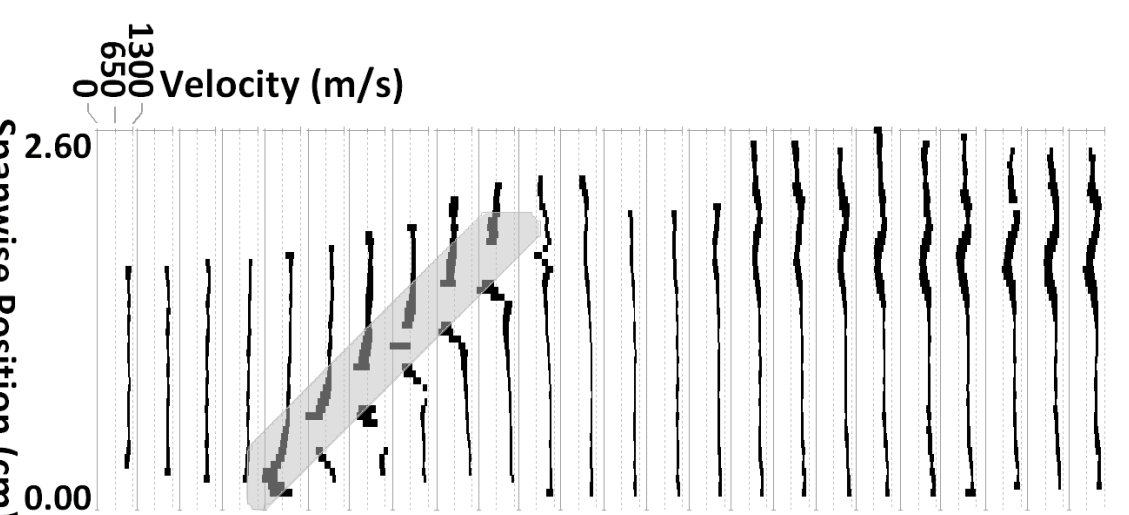

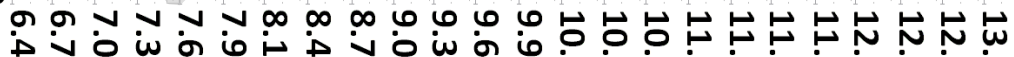
คे Streamwise Position (cm)

(c)

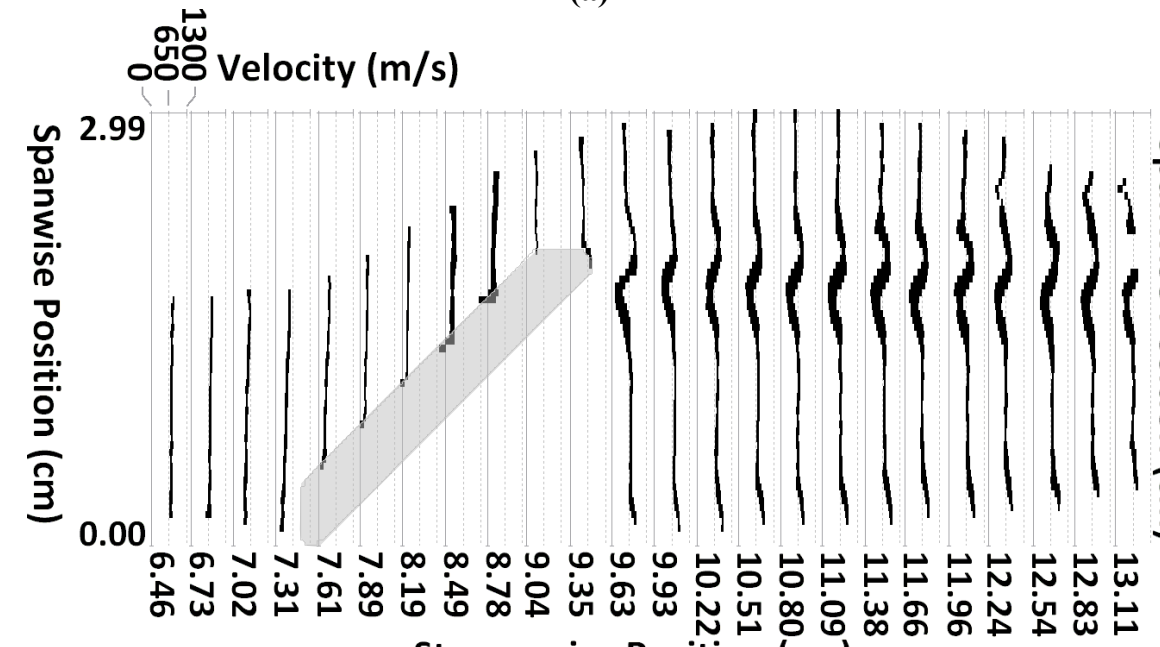

Streamwise Position $(\mathrm{cm})$

(b)

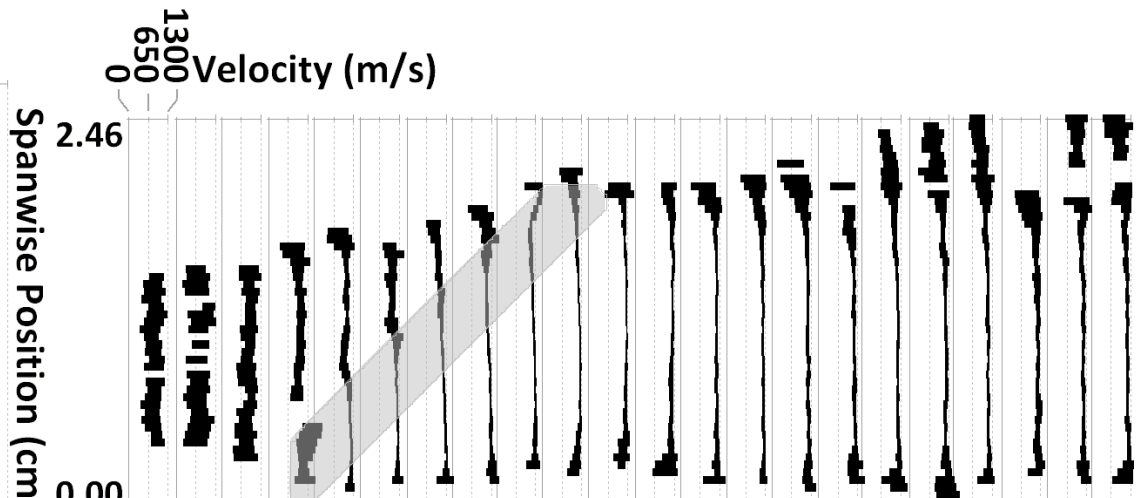

の ब ने 윔 Streamwise Position $(\mathrm{cm})$

(d)

Fig. 9 Plan-view mean velocity profiles with $2.5-\mathrm{mm}$ tall BLT DTO trip for $\operatorname{Re}_{\mathrm{x}}=1.7 \times 10^{6} \mathrm{~m}^{-1}$ at off-body positions of (a) $0.8-\mathrm{mm}$, (b) $1.1-\mathrm{mm}$, (c) 2.3 $\mathrm{mm}$, and (d) 3.4-mm. Estimated uncertainty in laser sheet position is $\pm 0.2-\mathbf{m m}$. 
should be performed in the future, or a methodology for scanning the laser sheet to acquire off-centerline side views should be developed.

Another observation is that there was a factor of 2 difference in the width of the excited lines in the flow $(0.7 \mathrm{~mm}$ versus $1.4 \mathrm{~mm}$ ). This was primarily caused by different placements of the cylindrical lens array. Generally, narrower lines result in more accurate and more precise velocity measurements. In future experiments, care should be taken to move the cylindrical lens array to minimize the width of these lines in the flow, thereby increasing both measurement accuracy and spatial precision.

It was noted several times in the text that measurements near the wall were corrupted by intense laser scatter, which depleted the phosphor, resulting in bad (unrealistic) velocity measurements near the wall. If precautions were taken to reduce scatter from the surface, it is possible that measurements would be able to be made much closer to the wall.

\section{Conclusion}

This paper has been produced to provide fundamental laminar flow velocity experimental data sets, with uncertainty, for comparison with hypersonic boundary layer CFD solutions. This paper represents the first application of the NO MTV technique to NASA Langley's 31-Inch Mach 10 Air Tunnel with the objective of obtaining multiple velocity datasets. The data presented in this paper have been provided at two unit Reynolds number conditions, $1.7 \times 10^{6} \mathrm{~m}^{-1}$ and $3.3 \times 10^{6} \mathrm{~m}^{-1}$, under unperturbed and perturbed flow conditions. For the perturbed flow conditions, three tripping elements were investigated: a $2-\mathrm{mm}$ tall by $4-\mathrm{mm}$ diameter cylindrical trip, a 1-mm tall BLT DTO trip, and a 2.5-mm tall BLT DTO trip. Data from two measurement plane orientations, side- and planview, were also provided. Additional TSP heat transfer measurements were provided to complement both the sideand plan-view velocity measurements.

\section{Acknowledgments}

We wish to acknowledge the expert contribution to this work from the 31-Inch Mach 10 Air tunnel and data system operators at NASA Langley Research Center. This work was supported by NASA's Fundamental Aeronautics Program, Hypersonics Project, Experimental Capabilities and Aerodynamics, Aerothermodynamics, and Plasma Disciplines.

\section{References}

${ }^{1}$ Berry, S.A., King, R.A., Kegerise, M.A., Wood, W.A., McGinley, C.B., Berger, K.T., and Anderson, B.P., "Orbiter Boundary Layer Transition Prediction Tool Enhancements," $48^{\text {th }}$ AIAA Aerospace Sciences Meeting, AIAA Paper 2010-246, January 4-7, 2010, Orlando, FL.

2 Chang, C-L., Choudhari, M.M., and Li, F., "Numerical Computations of Hypersonic Boundary-Layer over Surface Irregularities," 48 ${ }^{\text {th }}$ AIAA Aerospace Sciences Meeting, AIAA Paper 2010-1572, January 4-7, 2010, Orlando, FL.

${ }^{3}$ Danehy, P. M., Ivery, C. B., Inman, J. A., Bathel, B., Jones, S. B., McCrea, A. C., Jiang, N., Webster, M., Lempert, W., Miller, J., and Meyer, T., "High-speed PLIF imaging of hypersonic transition over discrete cylindrical roughness," $48^{\text {th }}$ AIAA Aerospace Sciences Meeting, AIAA Paper 2010-0703, January 4-7, 2010, Orlando, FL.

${ }^{4}$ Campbell, C.H., Garske, M.T., Kinder, J., and Berry, S.A., "Orbiter Entry Boundary Layer Flight Testing," $46{ }^{\text {th }}$ AIAA Aerospace Sciences Meeting and Exhibit, AIAA Paper 2008-635, January 7-10, 2008, Reno, NV.

${ }^{5}$ Horvath, T.J., Tomek, D.M., Berger, K.T., Splinter, S.C., Zalameda, J.N., Krasa, P.W., Tack, S., Schwartz, R.J., Gibson, D.M., Tietjen, A.B., "The HYTHIRM Project: Flight Thermography of the Space Shuttle During Hypersonic Re-entry," $48^{\text {th }}$ AIAA Aerospace Sciences Meeting, AIAA Paper 2010-241, January 4-7, 2010, Orlando, FL.

${ }^{6}$ Berry, S.A., Horvath, T.J., Schwartz, R., Ross, M., Anderson, B., and Campbell, C.H., "Infrared Imaging of Boundary Layer Transition Flight Experiments," 40th AIAA Thermophysics Conference, AIAA Paper 2008-4026, June 23-26, 2008, Seattle, WA.

${ }^{7}$ Anderson, B.P., Campbell, C.H., Saucedo, L.A., Kinder, G.R., Berger, K.T., "Boundary Layer Transition Flight Experiment Overview and In-Situ Measurements," 48 ${ }^{\text {th }}$ AIAA Aerospace Sciences Meeting, AIAA Paper 2010-240, January 4-7, 2010, Orlando, FL.

${ }^{8}$ Yoon, S., Barnhardt, M.D., and Candler, G.V., "Simulations of High-Speed Flow over an Isolated Roughness," 48 ${ }^{\text {th }}$ AIAA Aerospace Sciences Meeting, AIAA Paper 2010-1573, January 4-7, 2010, Orlando, FL.

${ }^{9}$ Choudhari, M.M., Li, F., Wu, M., Chang, C-L., Edwards, J., Kegerise, M., and King, R., "Laminar-Turbulent Transition behind Discrete Roughness Elements in a High-Speed Boundary Layer," $48^{\text {th }}$ AIAA Aerospace Sciences Meeting, AIAA Paper 20101575, January 4-7, 2010, Orlando, FL.

${ }^{10}$ Danehy, P.M., Garcia, A.P., Borg, S., Dyakonov, A.A., Berry, S.A., Inman, J.A., and Alderfer, D.W., "Fluorescence Visualization of Hypersonic Flow Past Triangular and Rectangular Boundary-Layer Trips," AIAA Paper 2007-536, 2007. 
${ }^{11}$ Danehy, P. M., Ivery, C. B., Bathel, B. F., Inman, J. A., Jones, S. B., Watkins, A. N., Goodman, K., McCrea, A., Leighty, B. D., and Lipford, W. K., "Orbiter BLT Flight Experiment Wind Tunnel Simulations: Nearfield Flow Imaging and Surface Thermography," AIAA Paper AIAA-2010-1571, 2010.

${ }^{12}$ Gendrich, C. P., Koochesfahani, M. M., “A spatial correlation technique for estimating velocity fields using molecular tagging velocimetry (MTV)," Experiments in Fluids, Vol. 22, pp. 67-77, 1996.

${ }^{13}$ Bathel, B.F., Danehy, P.M., Inman, J.A., Jones, S.B., Ivey, C.B., and Goyne, C.P., "Multiple Velocity Profile Measurements in Hypersonic Flows Using Sequentially-Imaged Fluorescence Tagging," $48^{\text {th }}$ AIAA Aerospace Sciences Meeting, AIAA Paper 2010-1404, January 4-7, Orlando, FL.

${ }^{14}$ Micol, J.R., "Langley Aerothermodynamic Facilities Complex: Enchancements and Testing Capabilities," AIAA 1998-0147, $36^{\text {th }}$ AIAA Aerospace Sciences Meeting, January 12-15, 1998, Reno, NV.

${ }^{15}$ Berry, S.A., Nowak, R.J., and Horvath, T.J., "Boundary Layer Control for Hypersonic Airbreathing Vehicles," AIAA 20042246, 34 ${ }^{\text {th }}$ AIAA Fluid Dynamics Conference and Exhibit, June 28 - July 1, 2004, Portland, Oregon, 2004.

${ }^{16}$ Danehy, P.M., Bathel, B.F., Ivey, C., Inman, J.A., and Jones, S.B., "NO PLIF study of hypersonic transition over a discrete hemispherical roughness element," $47^{\text {th }}$ AIAA Aerospace Sciences Meeting, AIAA Paper 2009-394, January 5-8, 2009, Orlando, FL.

${ }^{17}$ Watkins, A.N., Buck, G.M., Leighty, B.D., Lipford, W.E., and Oglesby, D.M., "Using Pressure- and Temperature-Sensitive Paint on the Aftbody of a Capsule Vehicle," AIAA Journal, Vol. 47, No. 4, pp. 821-829, 2009.

${ }^{18}$ Fay, J.A., and Riddell, F.R., "Theory of Stagnation Point Heat Transfer in Dissociated Air," J. Aero. Sci., Vol. 25, pp. 73-85, 1958.

19 Danehy, P.M., Alderfer, D.W., Inman, J.A., Berger, K.T., Buck, G.M., and Schwartz, R. J., "Fluorescence Imaging and Streamline Visualization of Hypersonic Flow over Rapid Prototype Wind-Tunnel Models," Proc. IMechE, Part G: J. Aerospace Engineering, 222(G5), 637-651, 2008.

20 Sanchez Sorzano, C.O., Thevenaz, P., and Unser, M., "Elastic Registration of Biological Images Using Vector-Spline Regularization," IEEE Transactions on Biomedical Engineering, 52 (4), pp. 652-663, April, 2005.

${ }^{21}$ Rasband, W.S., ImageJ, U. S. National Institutes of Health, Bethesda, MD, USA, http://rsb.info.nih.gov/ij, $1997-2009$. 